Full-length article

\title{
Using Magnesium to Maximize Heat Generated by Reactive Al/Zr Nanolaminates
}

Kyle R. Overdeep, ${ }^{a^{*}}$ Kenneth J. T. Livi, ${ }^{b}$ David J. Allen, ${ }^{c}$ Nick G. Glumac, ${ }^{c}$ Timothy P. Weihs. ${ }^{a}$

${ }^{\mathrm{a}}$ Johns Hopkins University

Department of Materials Science and Engineering

3400 N. Charles St.

Baltimore, MD 21218, USA

weihs@jhu.edu

* Corresponding Author: kyleoverdeep@jhu.edu, 1-401-300-9733

${ }^{\mathrm{b}}$ Johns Hopkins University

Department of Earth and Planetary Sciences

The HRAEM Facility of the Integrated Imaging Center

3400 N. Charles St.

Baltimore, MD 21218, USA

klivi@jhu.edu

${ }^{c}$ University of Illinois at Urbana-Champaign

Department of Mechanical Science and Engineering

1206 W Green St.

Urbana, IL 61801, USA

djallen2@illinois.edu, glumac@illinois.edu

\section{Abstract:}

In this study, we explore the effect of magnesium content on the ability of reactive nanocomposite foils to generate heat, by comparing three chemistries: $\mathrm{Al}: \mathrm{Zr}, \mathrm{Al}-8 \mathrm{Mg}: \mathrm{Zr}$, and Al-38Mg:Zr. These correspond to foils with alternating aluminum and zirconium layers where the $\mathrm{Al}$ is either pure, an 8 at.\% $\mathrm{Mg}$ alloy, or a 38 at.\% $\mathrm{Mg}$ alloy, respectively. Measurements performed in a specially designed bomb calorimeter show that $\mathrm{Al}-8 \mathrm{Mg}: \mathrm{Zr}$ foils perform the best, generating the greatest gravimetric heat in air, oxygen, and nitrogen environments. Both Mg-containing foils release a visible plume of particles and vapor upon reacting, which was recorded with a high speed camera. This ejected mass includes Mg vapor and particles of all three metals. Both the vapor and particles oxidize rapidly in air, resulting in single metaloxide particles. The reacted foils, particularly the Al-8Mg:Zr samples, contain voids and higher levels of oxygen and nitrogen throughout their thicknesses than reacted $\mathrm{Al}: \mathrm{Zr}$ foils. To 
explain the higher heats of reaction for the $\mathrm{Al}-8 \mathrm{Mg}: \mathrm{Zr}$ foils, we suggest that the out-diffusion and evaporation of $\mathrm{Mg}$ generates a high concentration of vacancies that enhance oxygen and nitrogen diffusion throughout the foil, thereby increasing the degree of oxidation and nitridation.

Keywords: reactive nanocomposites, bomb calorimetry, aluminum, zirconium, magnesium

\section{Introduction}

When nano-scale layers of components with large, negative heats of mixing are stacked together in an alternating fashion, a small energy input allows the layers to mix exothermically. If the heat generated within an ignition zone is enough to initiate rapid mixing in the surrounding layers, then the reaction will self-propagate throughout the entire system. This idea has been applied to systems with different microstructures and chemistries [1-3], including core-shell particles [4-8], powder compacts [9-14], mechanically activated foils and powders [15-19], and vapor-deposited laminate foils [2,20-28].

Here we explore vapor-deposited metal/metal systems that not only mix exothermically within milliseconds of ignition, but then also combust for extended durations on the order of seconds, to form oxides and nitrides, as shown schematically in Figure 1. With an effective choice of metals, the oxide and nitride formation reactions can release significantly more heat than the intermetallic formation reactions alone [29-31] (simply called “intermetallic reactions" henceforth). Such large heats can be used for bio-agent defeat, specifically against bacillus anthracis spores (anthrax), not only through direct thermal deactivation [32-35], but also by decomposing a mixture of precursor compounds to generate water [36,37] and biocidal iodine gas [38-40].

Although the complete combustion of elemental powders such as Al may theoretically produce more heat, nanolaminates are of interest because they can provide a relatively low 
ignition threshold that is independent of particle size, due to their small and controllable reactant spacing and their high heats of intermixing. Upon ignition, these reactions self-heat the nanolaminates to high temperatures where oxides and nitrides grow readily. This is particularly advantageous for metals that are relatively difficult to ignite as alloyed or elemental particles, but burn readily at high temperatures. In addition, the particle size can be varied to control the rate and temperature of oxide and nitride growth without impacting ignition. Other formulations are also being studied for the purpose of bio-agent defeat $[6,10,41-45]$.

We previously reported that a multilayer system with a 1:1 atomic ratio of $\mathrm{Al}$ and $\mathrm{Zr}$ leads to longer burn times than foils with $3 \mathrm{Al}: \mathrm{Zr}$ or $\mathrm{Al}$ :Ni chemistries, and therefore may be a good starting point for developing materials with tunable burning characteristics and the potential for significant heat production [31]. To further enhance heat generation, we now experiment with the addition of $\mathrm{Mg}$ to the $\mathrm{Al}$ layers in these $\mathrm{Al}: \mathrm{Zr}$ foils.

Al-Mg alloys are frequently used in pyrotechnics [46], and can lead to more complete combustion than pure $\mathrm{Al}$ particles because $\mathrm{Mg}$ will preferentially oxidize before $\mathrm{Al}$, but its oxide does not passivate the system as does $\mathrm{Al}_{2} \mathrm{O}_{3}$ [47]. $\mathrm{Mg}$ is also a more volatile metal, boiling at only $1091^{\circ} \mathrm{C}[48]$, and can potentially deform and fracture the reacting material as it boils, perhaps assisting the combustion process [49]. By using $\mathrm{Al}-\mathrm{Mg}$ alloys as an alternative to pure Al, we hope to leverage these advantageous properties to improve the system's extent of combustion and total heat release.

The current study is conducted using free-standing, sputter-deposited foils with alternating nano-scale layers of $\mathrm{Zr}$ and either $\mathrm{Al}, \mathrm{Al}-8 \mathrm{at} . \% \mathrm{Mg}$, or $\mathrm{Al}-38 \mathrm{at} . \% \mathrm{Mg}$. We characterize reaction temperatures, the ejection of vapor and particles, and the total heats of reaction in air, oxygen, and nitrogen. The compositions and morphologies of the final reaction 
products are examined using multiple techniques and the three reactive chemistries are compared in detail to identify the benefits of $\mathrm{Mg}$ within the $\mathrm{Al}$ layers.

\section{Experimental Methods}

\subsection{Fabrication}

Reactive multilayer foils were fabricated by DC magnetron sputtering, using targets purchased from Plasmaterials in Livermore, CA. The foils of interest were sputtered using 99.7 at.\% $\mathrm{Zr}$ targets, in conjunction with either $\mathrm{Al}-1100$ (min. 99 at.\% $\mathrm{Al}$ ), Al-8at.\% Mg, or Al-38at.\% Mg targets, all in atomic percent. A repeating $\mathrm{Al} / \mathrm{Zr}$ or $\mathrm{Al}-\mathrm{Mg} / \mathrm{Zr}$ bilayer structure was formed by sputtering onto brass substrates fixed to a water-cooled, rotating carousel. Power to each sputtering cathode was adjusted to select a certain deposition rate (and therefore layer thickness) that corresponds to the desired atomic ratio. Each set of samples had a maximum total thickness of approximately $40 \mu \mathrm{m}$, and a maximum bilayer spacing of approximately $80 \mathrm{~nm} .{ }^{1}$ The foils were removed from the substrates mechanically as specimens measuring $10 \mathrm{~mm}$ wide, and 55mm long.

We sputtered multilayer foils with three different compositions for this study: Al:Zr, Al8Mg: $\mathrm{Zr}$, and $\mathrm{Al}-38 \mathrm{Mg}: \mathrm{Zr}$. The colon is used to show a stoichiometric atomic ratio, indicating that the aluminum alloy and the zirconium have a 1:1 molar ratio. This notation indicates that Al-8Mg:Zr, for example, consists of layers of zirconium alternating with layers of an alloy that is 92 at.\% $\mathrm{Al}$ and 8 at.\% $\mathrm{Mg}$. These labels therefore provide nominal compositions calculated using the sputtering parameters, but elemental analysis of the as-fabricated foils show more $\mathrm{Al}$ and less $\mathrm{Zr}$ and $\mathrm{Mg}$ than expected for each sample type (see Table 1). We attribute the high $\mathrm{Al}: \mathrm{Mg}$ ratio to more scattering of $\mathrm{Mg}$ than $\mathrm{Al}$ in the plasma, and we attribute the higher $\mathrm{Al}: \mathrm{Zr}$ ratio to consistent small errors in the calibration of the $\mathrm{Al}, \mathrm{Al}-\mathrm{Mg}$, and $\mathrm{Zr}$ sputter rates.

\footnotetext{
${ }^{1}$ Maximum values are given because the fabrication process inherently leads to a range of thicknesses and bilayer spacings, due to the fact that the deposition rate is highest at the center of the substrate and decreases towards the outer edges. The thickness of the foils used ranged from $\approx 25-40 \mu \mathrm{m}$, with bilayers from $\approx 50-80 \mathrm{~nm}$.
} 
The three compositions used were selected based on our goal to compare samples with no $\mathrm{Mg}(\mathrm{Al}: \mathrm{Zr})$ against samples with a small amount of $\mathrm{Mg}(\mathrm{Al}-8 \mathrm{Mg}: \mathrm{Zr})$ and against samples with a large amount of $\mathrm{Mg}(\mathrm{Al}-38 \mathrm{Mg}: \mathrm{Zr})$. These two alloys were selected because they fall within a range commonly found in pyrotechnic formulations, and the $\mathrm{Al}-38 \mathrm{Mg}$ alloy is the first Al-rich intermetallic within the Al-Mg system. However, we note that sputtering from either target onto water-cooled substrates yielded solid solutions, as verified by XRD of the unreacted foils (Figure S1). Co-sputtering from an Al-8Mg target and an Al-38Mg target simultaneously to obtain intermediate compositions will allow for additional optimization in future efforts.

\subsection{Reaction Heats, Temperatures, and Products}

A NAC Memrecam HX-6 High Speed Camera was used to record the foils reacting at 10,000 to 50,000 frames per second. The foils were held horizontally in a metal frame, and an electrical spark from a $50 \mathrm{~V}$ power supply was applied at one end to initiate the reaction.

A two-color pyrometer, similar to one described in [50], was used to compare reaction temperatures as a function of time for the three chemistries. During these temperature measurements samples were held vertically, with the top and bottom edges clamped between glass slides to prevent the foils from folding during the reaction, while minimizing heatsinking effects. Ignition was achieved using an electrical spark from a power supply at $\approx 25 \mathrm{~V}$, connected to two electrodes at the bottom of the foil's exposed surface. The pyrometer was focused on a $1 \mathrm{~mm}$ diameter circle at the center of each foil.

The total heat generated by each sample was measured with a unique high-sensitivity bomb calorimeter that we designed and built specifically for these reactive foils. Experiments were conducted in air, pure oxygen, and pure nitrogen environments because an unknown mixture of these gases will be present for our final application. Tests were also performed in pure argon, in which only the intermetallic reactions can occur. An internal pressure of $\approx 1 \mathrm{~atm}$ 
was used for each test. For tests in air, oxygen, and nitrogen, the quantity of gas in the bomb is sufficient to completely oxidize or nitride the reactants, and only a small fraction of each is consumed $\left(\approx 1 \%\right.$ of $\mathrm{O}_{2}$ and $\approx 0.2 \%$ of $\left.\mathrm{N}_{2}\right)$. More detailed information about the instrument and its operation is available in [51].

Elemental maps of reacted foil cross-sections were collected on a JEOL JXA $8500 \mathrm{f}$ Electron Microprobe at the National Institute of Standards and Technology. Microscopy foil samples were reacted with an electrical spark while suspended in air, then fractured along their widths or down their lengths to obtain various cross-sectional views. Samples were then mounted in epoxy, polished to $1 \mu \mathrm{m}$, and carbon-coated to prevent charging. Regions of interest, such as exterior surfaces, pores, or different phases towards the center of the foil, were all analyzed for chemical composition in order to identify the mechanisms at play during these reactions.

\subsection{Characterization of Ejected Material}

Foils containing Mg discharged both vapor and particles during their reactions in all environments. The chemical species of the gaseous products from $\mathrm{Al}-8 \mathrm{Mg}: \mathrm{Zr}$ reactions were determined using atomic absorption and emission spectroscopy. We focused on the $8 \%-\mathrm{Mg}$ alloy because, as presented in the results below, it produces more heat than the $38 \%$ alloy and is therefore of greater interest. Tests were also performed on $\mathrm{Al}: \mathrm{Zr}$ samples for comparison. The foil samples were held horizontally and reacted in a small, windowed chamber. Light was passed through the reaction chamber $\approx 5 \mathrm{~mm}$ above the foil, directly through any vapor produced during the reaction. The light then continued out of the opposite window and into the spectrometer, in which a CCD camera sampled at $50 \mathrm{~Hz}$ for two seconds, automatically triggered at the ignition event. We used a xenon flash lamp as the broadband light source, set 
to flash at $50 \mathrm{~Hz}$ with $1200 \mathrm{~mJ}$ of energy per pulse, each pulse lasting $10 \mu \mathrm{s}$. Experiments were performed in air and argon environments, both at atmospheric pressure.

Because this technique only provides information for products in the vapor phase, TEMEELS (Transmission Electron Microscopy- Electron Energy Loss Spectroscopy) was performed to characterize the larger particles being ejected. The particles were collected for analysis by reacting foils in air and argon under $3 \mathrm{~mm}$ diameter, 200 mesh $\mathrm{Cu}$ grids with holey-carbon support films. The collected particles were then analyzed using a Philips CM300 Field Emission Gun TEM equipped with a Gatan GIF200 EELS detector.

The combination of the above techniques tells us what is being ejected, but not how much. To quantify the composition and mass of all the material expelled during the reactions, foils of each type (Al:Zr, Al-8Mg:Zr, and Al-38Mg:Zr) were reacted in sealed glass vials, so that all of the ejected mass, whether solid, liquid, or gas, was deposited onto the inside of the vial. The reacted foil was then extracted and put into a separate glass vial so that each sample was divided into two parts: one with just the ejected mass on the walls of the vial, and one with the reacted foil. Each vial was filled with a precise volume of several acids that fully digested the metals. Next, Inductively Coupled Plasma- Optical Emission Spectroscopy (ICP-OES) was performed upon the acid solutions by Galbraith Laboratories Inc. to identify the presence of each metal down to $0.5 \mu \mathrm{g}$. We then used the measured concentrations to calculate the total mass of each metal discharged, as well as the mass of each metal remaining in the foil.

\section{Results}

\subsection{Reaction Images and Temperatures}

High speed video footage of reactions in air shows that $\mathrm{Al}: \mathrm{Zr}$ foils do not eject material, and tend to maintain their basic morphology throughout their reactions. $\mathrm{Al}-8 \mathrm{Mg}: \mathrm{Zr}$ foils, however, discharge a cloud of vapor and particles as their intermetallic reaction propagates 
down the foil at $\approx 1.3 \mathrm{~m} \mathrm{~s}^{-1}$, and continue to expel vapor and particles for approximately $0.06 \mathrm{~s}$ after the formation reaction has passed that location. The foil then burns for about a quarter of a second, with no visible particles or vapor. The particles oxidize as they are ejected and can be seen dividing into multiple smaller pieces as they are projected away from the foil. Similar behavior is observed from $\mathrm{Al}-38 \mathrm{Mg}: \mathrm{Zr}$ foils, but their intermetallic reactions propagate more slowly $\left(\approx 0.45 \mathrm{~m} \mathrm{~s}^{-1}\right)$, and the expulsion of material occurs over a much broader range of time. Ejection of both vapor and particles begins at the start of the formation reaction and continues until the particle ejection abruptly stops after $\approx 0.4 \mathrm{~s}$, and the vapor gradually fades out with the oxidation reaction after an additional $0.1 \mathrm{~s}$. The rate of vapor production during the intermetallic reaction is much greater than during oxidation and nitridation, but particles are ejected at a consistent rate through both reaction stages. The still images in Figure $\mathbf{2}$ are taken from points in high speed videos that correspond to the end of the intermetallic reaction in order to show that there is no particle ejection from $\mathrm{Al}: \mathrm{Zr}$ foils, but $\mathrm{Mg}$-containing foils release a cloud of vapor and glowing hot particles. The Al-38Mg:Zr foils produce more vapor than the $\mathrm{Al}-8 \mathrm{Mg}: \mathrm{Zr}$ foils.

The foils frequently roll or curl when reacted in air, and the degree of rolling or curling appears to correlate with $\mathrm{Mg}$ content; the behavior is typically least severe with $\mathrm{Al}: \mathrm{Zr}$ foils, which experience only minor curling of the edges, as opposed to $\mathrm{Al}-38 \mathrm{Mg}: \mathrm{Zr}$ samples, in which the entire middle region can roll into a cylinder. Curled regions stay hot for a greater duration, and in one extreme case, such a region on an $\mathrm{Al}-38 \mathrm{Mg}: \mathrm{Zr}$ foil was observed to stay hot for $10.5 \mathrm{~s}$ after the rest of the foil had cooled. This severe case is atypical; the edges of most $\mathrm{Al}-38 \mathrm{Mg}: \mathrm{Zr}$ foils reacted in air continue to glow for approximately $2 \mathrm{~s}$ longer, but the behavior for foils of all types is irregular and unpredictable, so the range is broad. This curling effect does not occur for any foil reacted in argon.

In addition to imaging the reactions, we also investigated the temperature profiles for each foil-type. Averaged curves for the temperature profiles of the three Al-Mg alloys of interest 
$(0 \% \mathrm{Mg}, 8 \% \mathrm{Mg}$, and $38 \% \mathrm{Mg}$ ) are shown in Figure 3a.The initial spikes in temperature to approximately $1700 \mathrm{~K}$ are attributed to the intermetallic reactions, and are followed by a plateau associated with the foil burning at a slightly lower temperature. When reactions are performed in argon, the same intermetallic spikes appear but with no oxidation plateau. The pyrometry results in air show that $\mathrm{Al}: \mathrm{Zr}$ foils burn for approximately $2 \mathrm{~s}$ near $1600 \mathrm{~K}$. Al$8 \mathrm{Mg}: \mathrm{Zr}$ foils combust for a much shorter duration, $\approx 0.25 \mathrm{~s}$, but at the highest temperature; about $1675 \mathrm{~K}$. Al-38Mg: $\mathrm{Zr}$ foils have the lowest combustion temperature, at roughly $1500 \mathrm{~K}$, but burn for about twice as long as the Al-8Mg:Zr foils $(\approx 0.5 \mathrm{~s})$. For each of these, the temperatures are in a range where any $\mathrm{Al}$ or $\mathrm{Al}-\mathrm{Mg}$ phases will be molten [52], while $\mathrm{Zr}$ or $\mathrm{Zr}-\mathrm{Al}$ phases will be solid [53]. There are no $\mathrm{Zr}-\mathrm{Mg}$ phases because $\mathrm{Mg}$ and $\mathrm{Zr}$ are immiscible [54].

Figure $\mathbf{3 b}$ shows that such measurements are repeatable, though significant variations are measured if the pyrometer is focused on a region of the foil that happens to roll, as previously discussed. Although repeatability can be attained for a single set of experiments with identical foils, we estimate that the error in the temperature calibration is $\sim 100 \mathrm{~K}$. Also, foil composition may vary slightly between batches of foil samples, and combustion behavior is influenced by foil geometry. These factors may explain the slight discrepancy between these results and those presented previously in [31] for the Al:Zr samples.

\subsection{Total Heats of Reaction}

As our primary concern is a comparison of the total heat output between each foil chemistry, we designed and built a highly sensitive bomb calorimeter, specialized for reacting nanocomposite foils with masses on the order of $100 \mathrm{mg}$. Figure 4 shows the bomb calorimetry results for each chemistry in the four environments of interest: oxygen, air, nitrogen, and argon. The data reveal that the $\mathrm{Al}-8 \mathrm{Mg}: \mathrm{Zr}$ samples produced the most heat in each environment aside from argon, and were particularly superior in nitrogen, in which they 
generated approximately three times more energy per gram than the other two chemistries.

Experimental values were typically calculated as averages of at least three runs. ${ }^{2}$ Every sample reacted in oxygen collapsed to form a single large bead of product, suggesting that the foils were completely molten while reacting in this environment, and were able to reshape to minimize their surface area.

The theoretical maximum heat possible for each particular chemistry and environment was calculated by assuming complete oxidation of the foils when reacted in air and oxygen environments, and complete nitridation of the foils when reacted in nitrogen. The values were calculated by summing contributions from the literature values for standard enthalpies of formation for $\mathrm{Al}_{2} \mathrm{O}_{3}, \mathrm{ZrO}_{2}$ and $\mathrm{MgO}$; or for $\mathrm{AlN}, \mathrm{ZrN}$, and $\mathrm{Mg}_{3} \mathrm{~N}_{2}$, based on the predicted elemental composition [55].

The ratio of the experimental heats to theoretical heats can be thought of as the combustion efficiency, or the extent of the oxidation or nitridation. The combustion efficiency is higher for $\mathrm{Mg}$-containing samples than for $\mathrm{Al}: \mathrm{Zr}$ samples, with $\mathrm{Al}-8 \mathrm{Mg}: \mathrm{Zr}$ foils reaching almost $50 \%$ efficiency in oxygen and 40\% in nitrogen. Al-8Mg: $\mathrm{Zr}$ samples produced the most heat per gram in all three reactive environments, though $\mathrm{Al}-38 \mathrm{Mg}: \mathrm{Zr}$ foils perform similarly in oxygen. Theoretical maxima for samples reacted in argon are not visible because in an inert environment, only the intermetallic reactions are possible, and these all go to completion. Therefore, the measured values are approximately equal to the literature value for the heat of formation for the $\mathrm{AlZr}$ intermetallic [56] and decrease as $\mathrm{Mg}$ is added.

\footnotetext{
${ }^{2}$ Only two runs were performed for $\mathrm{Al}: \mathrm{Zr}$ samples in oxygen because molten globules of metal would fuse to the wall of the bomb during testing. Given the two runs were in good agreement, the third run was skipped to prevent damage to the calorimeter. Only one run was performed for $\mathrm{Al}-38 \mathrm{Mg}: \mathrm{Zr}$ samples in argon because reactions in these samples typically quenched immediately after ignition. We deemed it unnecessary to modify the calorimeter to obtain more data points for these tests because heat generated in argon is of less interest, and the single value obtained for the Al-38Mg: $\mathrm{Zr}$ foil matched expectations.
} 


\subsection{Reacted Foil Morphologies and Compositions}

Figure 5 compares foil cross sections taken across the width of $40 \mu \mathrm{m}$ thick samples that were reacted in air. The binary $\mathrm{Al}: \mathrm{Zr}$ samples oxidize on their outer surfaces only and are not porous, though we do see large bubbles forming between the oxide layer and the intermetallic central regions (Figure 5a,b). Al-8Mg:Zr samples have fewer large bubbles, but contain a high density of voids throughout, and show significant expansion to about $70 \mu \mathrm{m}$ in thickness (Figure $5 \mathrm{c}, \mathrm{d}$ ). Analysis of the Al-8Mg: $\mathrm{Zr}$ foil cross section in Figure $5 \mathrm{~d}$ indicates that voids account for $64 \%$ of the total area, though porosity is highly variable and more dense regions of the same foil are only about $37 \%$ porous. The Al-38Mg:Zr samples (Figure 5e,f) are typically more dense, with approximately $21 \%$ porosity, mostly concentrated at the surfaces. In general, the Al-38Mg:Zr samples also have the most variability within each cross section, as shown in Figure 5e. Some segments are reduced to about $5 \mu \mathrm{m}$ in thickness, while other segments expand up to $100 \mu \mathrm{m}$. Each cross section in Figure 5 was taken across the width of the sample, approximately halfway along the foil's length, where the most significant oxidation occurs. It is evident from the mosaics of the foil widths that the severity of rolling while reacting is a function of $\mathrm{Mg}$-content, since the reacted $\mathrm{Al}: \mathrm{Zr}$ foil remains relatively flat while the Al-38Mg: $\mathrm{Zr}$ cross section has experienced a dramatic change in shape. All foils in Figure 5 were originally $10 \mathrm{~mm}$ wide, but the $\mathrm{Al}: \mathrm{Zr}$ foil broke during the mounting process, and the Al-38Mg:Zr foil curled and shriveled to the point that it's width is greatly reduced.

While elemental data is not shown in Figure 5, it was collected for a variety of regions across many foils that were reacted in air. The elemental maps for the Al-8Mg: $\mathrm{Zr}$ and Al$38 \mathrm{Mg}: \mathrm{Zr}$ foil cross sections displayed in the Figure 5 can be found in the Supplementary Material (Figures S2,S3), and a map of an Al:Zr foil cross section can be found in [31]. Oxygen and nitrogen are found at their highest concentrations on the exterior surfaces of each 
reacted foil, with lower levels throughout the central regions. The amounts of $\mathrm{N}$ and $\mathrm{O}$ in only the inner-most regions of each foil are listed in Table 2, and it is evident that much higher levels of $\mathrm{O}$ and $\mathrm{N}$ are present in the center of the $\mathrm{Al}-8 \mathrm{Mg}: \mathrm{Zr}$ foils compared to the other two chemistries. The values for Al-8Mg:Zr and Al-38Mg:Zr samples are the total compositions measured in a rectangular area extending about $100 \mu \mathrm{m}$ across the foil width and $10 \mu \mathrm{m}$ across the center of the foil thickness. Values were observed to fluctuate severely with local morphology; for example, localized zones in Al-8MgZr samples reach as high as 40 at.\% N, while thicker, more dense areas of $\mathrm{Al}-38 \mathrm{Mg}: \mathrm{Zr}$ foils had oxygen and nitrogen levels as low as 1 at.\%. The values for Al:Zr samples, however, are from earlier experiments and are taken from the average of two points in the interior of the foil, but there is far less variability in these foils and so the values are accurate representations. The representative cross sections used for these analyses are those provided in Figure 5.

\subsection{Characterization of Ejected Material}

Atomic absorption and emission spectroscopy confirm that $\mathrm{Mg}$ vaporizes during the reaction of $\mathrm{Al}-8 \mathrm{Mg}: \mathrm{Zr}$ foils in air and in argon, as indicated by the sharp $\mathrm{Mg}$ atomic absorption peak appearing at $285 \mathrm{~nm}$ [57], $0.01 \mathrm{~s}$ after Al-8Mg:Zr samples are reacted in either environment (Figure 6a and Figure 6b). The characteristic peaks for the possible metal oxides are found at slightly higher wavelengths [58-62], shown in Figure 6c where we see a series of $\mathrm{MgO}$ emission peaks from $\mathrm{Al}-8 \mathrm{Mg}: \mathrm{Zr}$ samples reacted in air. $\mathrm{MgO}$ peaks are already present in the earliest possible measurement at $\mathrm{t}=0.01 \pm .01 \mathrm{~s}$, alongside a set of atomic $\mathrm{Mg}$ emission peaks at $516-518 \mathrm{~nm}$. No $\mathrm{Al}$ or $\mathrm{Zr}$ peaks were observed after reacting the $\mathrm{Al}: \mathrm{Zr}$ and Al-8Mg:Zr samples in either air or argon. We can assume that the same species would vaporize from $\mathrm{Al}-38 \mathrm{Mg}: \mathrm{Zr}$ foils, and so we focused on the $8 \%-\mathrm{Mg}$ alloy because, as 
presented in Section 2.2, it produces more heat than the 38\% alloy and is therefore of greater interest.

Although these tests show that $\mathrm{Mg}$ and only $\mathrm{Mg}$ is vaporizing, this spectroscopic technique cannot detect the larger particles we see being ejected in high speed videos of these reactions. TEM-EELS (Transmission Electron Microscopy- Electron Energy Loss Spectroscopy) was therefore performed on particles discharged in air, after collecting them on TEM grids held above reacting $\mathrm{Al}-8 \mathrm{Mg}: \mathrm{Zr}$ foils. The analysis reveals that homogeneous $\mathrm{MgO}, \mathrm{ZrO}_{2}$, and $\mathrm{Al}_{2} \mathrm{O}_{3}$ particles are present, with a wide variety of shapes and sizes, as depicted in Figure 7. Each particle is a single metal oxide; no particles contained more than one metal, and no unoxidized metals are found on the carbon grid.

Spectroscopy of the vapor and TEM analysis of the particles effectively tell us what is being ejected from reacting foils, but neither technique provides information regarding the quantity of each metal being ejected. For this, ICP-OES of reacted foils and their ejected particles and vapor was performed. The results in Figure $\mathbf{8}$ show that the percent of metal ejected increases with increasing $\mathrm{Mg}$ content, going from negligible amounts from $\mathrm{Al}: \mathrm{Zr}$ samples, to 4.0 at.\% for $\mathrm{Al}-38 \mathrm{Mg}: \mathrm{Zr}$ samples. Most of the ejected material is $\mathrm{Mg}: 2.2 \%$ of the 2.9\% discharged from $\mathrm{Al}-8 \mathrm{Mg}: \mathrm{Zr}$ foils, and 3.7\% of 4.0\% discharged from $\mathrm{Al}-38 \mathrm{Mg}: \mathrm{Zr}$ foils. It should be noted that although more $\mathrm{Mg}$ was ejected from $\mathrm{Al}-38 \mathrm{Mg}: \mathrm{Zr}$ samples, it is a much smaller fraction of the initial $\mathrm{Mg}$ content than is released from $\mathrm{Al}-8 \mathrm{Mg}: \mathrm{Zr}$ samples, for which more $\mathrm{Mg}$ was found outside the foil (2.2\%) than remaining within the foil (1.6\%).

\section{Discussion}

In an earlier study, temperature-time data gained from pyrometry measurements was used to estimate the heat produced by $\mathrm{Al}: \mathrm{Zr}$ foils reacting in air [31]. This simple analysis, if utilized here, suggests that $\mathrm{Al}: \mathrm{Zr}$ foils produce the most total heat, and $\mathrm{Al}-8 \mathrm{Mg}: \mathrm{Zr}$ foils 
produce the least. However, the comparison has multiple shortcomings. First, it assumes that the pyrometer is completely emissivity independent and that convective and conductive heat losses are insignificant. Furthermore, the pyrometer only measures temperature at a single point approximately $1 \mathrm{~mm}$ in diameter on the surface of the foils, which is assumed to represent temperature across the entire sample, and gives no information regarding the temperature field surrounding the foil or for the ejected mass. These imperfect assumptions are compounded by differences in foil behavior or properties such as the degree of curling, mass ejection, and surface roughness, which we believe may be significant enough to influence the reported trends. Thus, a more direct measurement of heat production was utilized in this study, namely bomb calorimetry.

The bomb calorimetry data in Figure 4 shows that $\mathrm{Mg}$ is a helpful addition to the $\mathrm{Al} / \mathrm{Zr}$ multilayer foils and leads to increases in total heat production in all reactive environments. The heat generated by $\mathrm{Al}-8 \mathrm{Mg}: \mathrm{Zr}$ and $\mathrm{Al}-38 \mathrm{Mg}: \mathrm{Zr}$ foils reacted in oxygen are both about 24\% higher than $\mathrm{Al}: \mathrm{Zr}$ foils. The presence of $\mathrm{Mg}$ is even more helpful in air and nitrogen, which better represent the environments of concern for our application. The largest increase was a $2.7 \mathrm{x}$ improvement between $\mathrm{Al}: \mathrm{Zr}$ and $\mathrm{Al}-8 \mathrm{Mg}: \mathrm{Zr}$ foils reacting in nitrogen.

Increasing the ratio of $\mathrm{Mg}$ from $\mathrm{Al}-8 \mathrm{Mg}: \mathrm{Zr}$ to $\mathrm{Al}-38 \mathrm{Mg}: \mathrm{Zr}$, though, decreases total heat output in each environment tested. In the inert argon environment, the heat production dropped by $8 \%$, which is less than expected given that an additional $30 \%$ of the $\mathrm{Al}$ was replaced with $\mathrm{Mg}$ which is immiscible with $\mathrm{Zr}$ [54]. It is possible that the drop in intermetallic reaction heat was less severe than expected with the addition of $\mathrm{Mg}$ because that $\mathrm{Mg}$ vaporizes and may react with the small amount of oxygen remaining in the bomb after purging. The heat output decreases by only $4 \%$ in oxygen, but by $23 \%$ in air and by $68 \%$ in nitrogen. These large decreases in air and nitrogen cannot be attributed to $\mathrm{Mg}$ having a lower heat of combustion than $\mathrm{Al}$, since the theoretical maximum drops by only $3.1 \%$ between $\mathrm{Al}-$ 8Mg:Zr and Al-38Mg:Zr samples in air, and by $6.8 \%$ in nitrogen, as shown in Figure 4. One 
possible explanation is that higher $\mathrm{Mg}$ content lowers the combustion temperature due to greater evaporative cooling. Another explanation is the larger degree of curling for the Al$38 \mathrm{Mg}: \mathrm{Zr}$ samples reduces the exposed surface area and might limit the rate of combustion. Either of these factors could lower the oxidation/nitridation temperature following the initial intermetallic reaction, as suggested by the temperature profiles in Figure 3. This in turn could lower heat production as reported in Figure 4.

The duration of burning seems to follow a pattern opposite to that of heat production: it drastically decreases when $\mathrm{Mg}$ is added, going from $\approx 2 \mathrm{~s}$ for $\mathrm{Al}: \mathrm{Zr}$ foils to $\approx 0.25 \mathrm{~s}$ for $\mathrm{Al}-8 \mathrm{Mg}$ foils, but then increases back up to $\approx 0.5 \mathrm{~s}$ for Al-38Mg:Zr foils. The duration of combustion is likely governed by the balance between heat production through oxidation and nitridation and heat losses via radiation and evaporation. Each of these factors depends upon Mg content, but their roles in determining the net impact of $\mathrm{Mg}$ on combustion duration are not yet known. Consider, for example, the fact that the extent of rolling and curling increases with $\mathrm{Mg}$ content. As noted above, greater curling should limit exposed surface areas for samples and hence combustion rates and potentially combustion duration. However, the reduced surface area will also reduce radiative cooling and therefore may extend the period of combustion. Thus, the net impact is unclear. Further still, the degree of curling varies within the high $\mathrm{Mg}$ content foils, which explains their larger standard deviations (Figure 4). Clearly, more studies are needed to fully understand the influence of $\mathrm{Mg}$ content on combustion duration, rate, and temperature.

Calorimetric measurements show that no foil, of any type, produced more than $49 \%$ of its theoretical maximum heat of combustion, even when reacted in pure oxygen. Thus, far more heat can be gained by increasing the extent of reaction, and so it is important to understand how $\mathrm{Mg}$ helps this process in order to increase heat production above $50 \%$ of the theoretical maximum. We now consider two mechanisms by which a small amount of $\mathrm{Mg}$ is able to increase total heat production in these foils: 
First, Mg leads to the ejection of foil mass that oxidizes completely once outside of the foil, providing a boost to combustion efficiency. $\mathrm{Mg}$ is very volatile compared to $\mathrm{Al}$ and $\mathrm{Zr}$ [63], with a boiling point of only $1091^{\circ} \mathrm{C}$, compared to $2519^{\circ} \mathrm{C}$ and $4409^{\circ} \mathrm{C}$ for $\mathrm{Al}$ and $\mathrm{Zr}$, respectively [48]. Not only does the $\mathrm{Mg}$ itself vaporize and likely form the majority of the observed $\mathrm{MgO}$ particles, it also leads to the discharge and subsequent complete oxidation of some $\mathrm{Al}$ and $\mathrm{Zr}$ as well, in the form of micron-scale metallic particles. Particle ejection must at least be assisted by, if not enabled by, the presence of $\mathrm{Mg}$, as both $\mathrm{Mg}$-containing foils eject particles, while Al:Zr foils experience negligible mass loss (Figure 8) and high speed footage of their reactions shows no visible material expulsion (Figure 2). Similar behavior has been reported for $\mathrm{Zr}$ burning in oxygen/nitrogen environments [64-67]. The mechanism determined in these studies involves $\mathrm{Zr}$ taking up nitrogen early in the combustion process, but then displacing it with the thermodynamically favored oxygen after burning for longer durations. This liberates the nitrogen, causing the composition to exceed the solubility limit in the metal, resulting in pressure buildup and a subsequent explosion when the internal pressure overcomes the cohesive energy of the molten metal. This mechanism may indeed contribute to particle ejection, but we do not believe it is the primary mechanism because this would occur for Al:Zr foils as well, not just Al-8Mg:Zr and Al-38Mg:Zr foils.

The ejected particles are likely molten, given that they can reach higher combustion temperatures than the bulk foils where the temperature is being measured, and will therefore be well above the melting points for any Al-Mg phase [52]. They may also be above those for some Al-Zr phases as well [53]. High speed videos of reactions for $\mathrm{Al}-8 \mathrm{Mg}: \mathrm{Zr}$ and $\mathrm{Al}$ 38Mg: $\mathrm{Zr}$ foils show that the ejected particles explode into many smaller pieces shortly after ejection. The explosion likely occurs from a combination of the two mechanisms discussed above; the boiling of $\mathrm{Mg}$ and the dissolution of $\mathrm{N}$, occurring in tandem within the particle's interior to cause the sudden explosion. This will be examined in the near future by performing the reactions in pure oxygen to determine if nitrogen is required for this behavior to occur. 
TEM-EDS shows that all of the ejected material oxidizes completely in air because no pure metals were found, only their oxides. In addition, only one species of metal-oxide is present in each particle, either $\mathrm{Al}_{2} \mathrm{O}_{3}, \mathrm{ZrO}_{2}$, or $\mathrm{MgO}$, but never a mixture. The particles ejected in argon, however, contain all three elements, suggesting that particles are initially ejected as molten globules of mixed metals. The separation that follows ejection could occur if $\mathrm{Al}$ and $\mathrm{Mg}$ evaporate from the burning particles, resulting in $\mathrm{Al}$ vapor, $\mathrm{Mg}$ vapor, and a $\mathrm{Zr}$ particle, each of which oxidizes in air and remain separate as immiscible oxides [68]. Alternatively, immiscible metal oxides may form within the particles themselves, and separate into smaller particles upon the explosion event. Both of these arguments are consistent with the highspeed videos showing hot particles exploding into many smaller particles after ejection in air.

Although the driving force for the expulsion of particles and their subsequent explosions into many smaller pieces is intriguing, we are primarily concerned with how these processes affect the total heat production. The complete oxidation of all ejected mass, quantified in Figure 8, contributes $0.34 \mathrm{~kJ} \mathrm{~g}^{-1}$ for Al-8Mg: $\mathrm{Zr}$ foils, and $0.53 \mathrm{~kJ} \mathrm{~g}^{-1}$ for $\mathrm{Al}-38 \mathrm{Mg}: \mathrm{Zr}$ foils. These values correspond to $14 \%$ and $21 \%$ increases in heat, respectively, compared to $\mathrm{Al}: \mathrm{Zr}$ foils reacted in air. Although significant, these sums alone cannot fully explain the large heat gains we measured with the addition of $\mathrm{Mg}$.

We therefore argue that the second and most significant impact of $\mathrm{Mg}$ is to enhance the diffusion of oxygen and nitrogen into and through the foil. The presence of even small amounts of $\mathrm{Mg}$ in the zirconia phase that forms on the outside of the foils should create oxygen vacancies in the $\mathrm{ZrO}_{2}$. These will in turn enhance oxygen diffusion in the growing oxide $[69,70]$. In a similar manner, the evaporation of $\mathrm{Mg}$ from the foils should lead to a diffusion of $\mathrm{Mg}$ to foil surfaces that must be balanced by an inward flux of vacancies. This inward flux will increase the concentration of vacancies within the metallic regions of the burning foils, thereby increasing the rate of diffusion and the resulting oxidation and 
nitridation $[71,72]$. As a consequence, heat production would also increase. The results provided in Table 2 support this argument, showing that the central regions of the $\mathrm{Al}-8 \mathrm{Mg}: \mathrm{Zr}$ foils have approximately $4 \mathrm{x}$ more oxygen and nitrogen in comparison to the $\mathrm{Al}: \mathrm{Zr}$ foils, which would explain the large increases in heat measured by bomb calorimetry.

The Al-8Mg: $\mathrm{Zr}$ foil cross sections in Figure 5 show the existence of voids that are too large to result from the coalescence of excess vacancies alone. Instead, these voids likely nucleate from the vacancies and then grow as the oxides and nitrides form and force volume expansion within these foils. The associated stresses can be significant enough to promote void growth, as well as delamination between adjacent phases. The elemental maps of foil cross sections in the Supplementary Material (Figures S2,S3) show that oxygen, nitrogen, and magnesium are not found in higher concentrations at the internal surfaces of the voids, suggesting that they are completely enclosed and do not serve as channels for gas flow as we had originally hypothesized, and are therefore unlikely to be responsible for increasing combustion efficiency. The absence of nitrogen within these voids also suggests that it is unlikely that they result from the dissolution of $\mathrm{N}$ in the later stages of combustion. Fewer voids are seen in Al-38Mg:Zr samples, as we would expect based on their lower oxide and nitride contents, and therefore smaller growth stresses. Stresses due to oxide growth likely generate the large voids at the outer surfaces of $\mathrm{Al}: \mathrm{Zr}$ foils as well. We believe that the growing oxide buckles away from the underlying intermetallic in these locations, in order to relieve the compressive growth stresses.

Last, we address the kinetic competition between oxide growth and nitride growth when foils are reacted in air. Even though $\mathrm{ZrO}_{2}$ is thermodynamically more stable than $\mathrm{ZrN}$, XRD results for foils reacted in air, and the correlation between $\mathrm{Zr}$ and $\mathrm{N}$ concentrations in elemental maps, both show that $\mathrm{ZrN}$ does form in all samples. In fact, microprobe data in Table 2 shows that nitrogen is more highly represented within the foils than oxygen. This 
suggests that kinetics are dominating instead of thermodynamics. The higher concentration of nitrogen in air (78 at.\% $\mathrm{N}_{2}$ and only 21 at. $\% \mathrm{O}_{2}$ ) [73] should lead to higher impingement and adsorption rates for nitrogen compared to oxygen. In addition, very thin depletion zones of oxygen may develop near the foils surface. In both cases, fewer oxygen atoms and more nitrogen atoms will diffuse into the foil and nitride formation will be favored kinetically. While undesirable in many cases, the formation of nitrides can be beneficial in applications where oxygen may be limited.

Looking forward, the sputtered $\mathrm{Al}-\mathrm{Mg} / \mathrm{Zr}$ system serves as a prototype for a three-pronged approach to maximizing heat production by particle combustion: First, an intermetallic reaction brings the entire mass to high temperatures where oxidation occurs readily. Second, oxidation and nitridation is extended to relatively long durations via appropriate material selection. Lastly, the vaporization of at least one component enhances combustion efficiency. Using this combined strategy, we hope to investigate heat produced by other reactive nanocomposite systems that could utilize these mechanisms and potentially produce even larger quantities of heat than the $\mathrm{Al}-\mathrm{Mg} / \mathrm{Zr}$ chemistry.

\section{Conclusion}

We have shown that alloying aluminum with magnesium increases heat generation in $\mathrm{Al} / \mathrm{Zr}$ multilayer foils that are reacted in air, oxygen or nitrogen. The presence of $\mathrm{Mg}$ leads to the evaporation of $\mathrm{Mg}$ and the ejection of alloyed metal particles. Both the $\mathrm{Mg}$ vapor and the metal particles oxidize rapidly and the particles split into single metal oxides. While the $\mathrm{Al}: \mathrm{Zr}$ foils burn longer in air according to pyrometry studies, Al-8Mg: $\mathrm{Zr}$ and $\mathrm{Al}-38 \mathrm{Mg}: \mathrm{Zr}$ foils produce more heat, as measured with a specially designed bomb calorimeter. The Al-8Mg: $\mathrm{Zr}$ foils generate the most heat of all three chemistries from reactions in air, oxygen and nitrogen. We propose two general mechanisms to explain the higher heat production. One is that the 
evaporated $\mathrm{Mg}$ and the ejected metal particles all oxidize completely, thereby increasing combustion efficiency. The other is that the presence of Mg enhances diffusion of oxygen and nitrogen through the foil and thereby increases combustion efficiency even further: $\mathrm{Mg}$ in the

growing $\mathrm{ZrO}_{2}$ layers should enhance oxygen and nitrogen diffusion by creating oxygen vacancies, and in a similar manner, as $\mathrm{Mg}$ evaporates from the foils, the outward flux of $\mathrm{Mg}$ is balanced by an inward flux of vacancies that should enhance the diffusion of oxygen and nitrogen into the foil. The suggested enhancement of diffusion into $\mathrm{Mg}$-containing foils is supported by electron microprobe elemental maps of reacted samples that show more oxygen and nitrogen in the center of the foils, compared to $\mathrm{Al}: \mathrm{Zr}$ foils with no $\mathrm{Mg}$.

\section{Acknowledgements}

The authors would like to acknowledge Howie Joress and Sara Barron for their previous work on the project. We also appreciate the programming and instrumentation help provided by Michael Grapes, and the microprobe work performed by Dr. Douglas Meier. The bomb calorimeter was fabricated in the JHU machine shop by Francis Cook and Mike Franckowiak. This work is funded by DTRA, grant HDTRAA1-11-1-0063.

\section{References}

[1] E.L. Dreizin, Prog. Energy Combust. Sci. 35 (2009) 141-67.

[2] A.S. Rogachev, Russ. Chem. Rev. 77 (2008) 21-37.

[3] T.P. Weihs, in:, K. Barmak, K.R. Coffey (Eds.), Metallic Films for Electronic, Optical and Magnetic Applications, Woodhead, Swaston, UK, 2014, pp. 160-243.

[4] A. Prakash, A. V. McCormick, M.R. Zachariah, Nano Lett. 5 (2005) 1357-60.

[5] D.S. Sundaram, V. Yang, Combust. Flame 161 (2014) 2916-23. 
[6] J. Feng, G. Jian, Q. Liu, M.R. Zachariah, ACS Appl. Mater. Interfaces 5 (2013) 887580 .

[7] E. V. Levchenko, A. V. Evteev, D.P. Riley, I. V. Belova, G.E. Murch, Comput. Mater. Sci. 47 (2010) 712-20.

[8] J.D.E. White, R. V Reeves, S.F. Son, A.S. Mukasyan, J. Phys. Chem. A 113 (2009) $13541-47$.

[9] S. Yan, G. Jian, M.R. Zachariah, ACS Appl. Mater. Interfaces 4 (2012) 6432-35.

[10] K.T. Sullivan, N.W. Piekiel, S. Chowdhury, C. Wu, M.R. Zachariah, C.E. Johnson, Combust. Sci. Technol. 183 (2010) 285-302.

[11] S.W. Dean, J.K. Potter, R. a. Yetter, T.J. Eden, V. Champagne, M. Trexler, Intermetallics 43 (2013) 121-30.

[12] H.P. Li, J. a. Sekhar, J. Mater. Res. 10 (1995) 2471-80.

[13] S. Dong, P. Hou, H. Yang, G. Zou, Intermetallics 10 (2002) 217-23.

[14] E.M. Hunt, M.L. Pantoya, J. Appl. Phys. 98 (2005) 034909.

[15] J.S. Benjamin, Met. Powder Rep. 45 (1990) 122-27.

[16] L. Lu, Y.F. Zhang, J. Alloys Compd. 290 (1999) 279-83.

[17] C.E. Wen, K. Kobayashi, T. Sugiyama, T. Nishio, A. Matsumoto, J. Mater. Sci. 35 (2000) 2099-2105.

[18] A.K. Stover, N.M. Krywopusk, G.M. Fritz, S.C. Barron, J.D. Gibbins, T.P. Weihs, J. Mater. Sci. 48 (2013) 5917-29.

[19] A.S. Rogachev, N.F. Shkodich, S.G. Vadchenko, F. Baras, D.Y. Kovalev, S. Rouvimov, A.S. Nepapushev, A.S. Mukasyan, J. Alloys Compd. 577 (2013) 600-605.

[20] T.P. Weihs, in:, D. Glocker, S. Shah (Eds.), Handbook of Thin Film Process Technology, IOP Publishing Ltd, Bristol, UK, 1997.

[21] E. Ma, C. V. Thompson, L.A. Clevenger, K.N. Tu, Appl. Phys. Lett. 57 (1990) $1262-$ 64.

[22] D.P. Adams, M.A. Rodriguez, J.P. McDonald, M.M. Bai, E. Jones, L. Brewer, J.J. Moore, J. Appl. Phys. 106 (2009) 093505.

[23] R. Knepper, M.R. Snyder, G. Fritz, K. Fisher, O.M. Knio, T.P. Weihs, J. Appl. Phys. 105 (2009) 083504.

[24] C.J. Morris, B. Mary, E. Zakar, S. Barron, G. Fritz, O. Knio, T.P. Weihs, R. Hodgin, P. Wilkins, C. May, J. Phys. Chem. Solids 71 (2010) 84-89. 
[25] S. Barron, R. Knepper, N. Walker, T.P. Weihs, J. Appl. Phys. 109 (2011) 013519.

[26] K. Fisher, S.C. Barron, M. a. Bonds, R. Knepper, K.J.T. Livi, G.H. Campbell, N.D. Browning, T.P. Weihs, J. Appl. Phys. 114 (2013) 243509.

[27] S.C. Barron, S.T. Kelly, J. Kirchhoff, R. Knepper, K. Fisher, K.J.T. Livi, E.M. Dufresne, K. Fezzaa, T.W. Barbee, T.C. Hufnagel, T.P. Weihs, J. Appl. Phys. 114 (2013) 223517.

[28] D.P. Adams, Thin Solid Films 576 (2015) 98-128.

[29] T.P. Weihs, T.W.J. Barbee, M.A. Wall, MRS Proc. 382 (1995) 21-26.

[30] S.S. Zumdahl, Chemical Principles, 6th ed., Houghton Mifflin Company, 2009.

[31] H. Joress, S. Barron, K.J.T. Livi, N. Aronhime, T.P. Weihs, Appl. Phys. Lett. 101 (2012) 111908.

[32] S. Xu, T.P. Labuza, F. Diez-Gonzalez, Appl. Environ. Microbiol. 72 (2006) 4479-83.

[33] V.K. Juneja, A.C.S. Porto-Fett, J.E. Call, H.B. Marks, M.L. Tamplin, J.B. Luchansky, Innov. Food Sci. Emerg. Technol. 11 (2010) 123-29.

[34] F.F. Busta, Appl. Microbiol. 15 (1967) 640-45.

[35] T.J. Montville, R. Dengrove, T. De Siano, M. Bonnet, D.W. Schaffner, J. Food Prot. 68 (2005) 2362-66.

[36] T.L. Buhr, A.A. Young, Z.A. Minter, C.M. Wells, D.C. McPherson, C.L. Hooban, C.A. Johnson, E.J. Prokop, J.R. Crigler, J. Appl. Microbiol. 113 (2012) 1037-51.

[37] A.L. Reyes, R.G. Crawford, A.J. Wehby, J.T. Peeler, J.C. Wimsatt, J.E. Campbell, R.M. Twedt, Appl. Environ. Microbiol. 42 (1981) 692-97.

[38] S.P. Gorman, E.M. Scott, E.P. Hutchinson, J. Appl. Bacteriol. 59 (1985) 99-105.

[39] S.F. Bloomfield, R. Megid, J. Appl. Bacteriol. 76 (1994) 492-99.

[40] L. Gershenfeld, B. Witlin, J. Am. Pharm. Assoc. Am. Pharm. Assoc. (Baltim). 41 (1952) 451-52.

[41] S.A. Grinshpun, A. Adhikari, M. Yermakov, T. Reponen, E. Dreizin, M. Schoenitz, V. Hoffmann, S. Zhang, Environ. Sci. Technol. 46 (2012) 7334-41.

[42] S. Zhang, C. Badiola, M. Schoenitz, E.L. Dreizin, Combust. Flame 159 (2012) 198086.

[43] S. Zhang, M. Schoenitz, E.L. Dreizin, J. Phys. Chem. C 114 (2010) 19653-59.

[44] B.R. Clark, M.L. Pantoya, Phys. Chem. Chem. Phys. 12 (2010) 12653-57. 
[45] D. Fischer, T.M. Klapötke, J. Stierstorfer, Zeitschrift Für Anorg. Und Allg. Chemie 637 (2011) 660-65.

[46] J.A. Conkling, Chemistry of Pyrotechnics: Basic Principles and Theory, Marcel Dekker, Inc., New York, NY, 1985.

[47] M. Schoenitz, E.L. Dreizin, J. Propuls. Power 20 (2004) 1064-68.

[48] W.M. Haynes, CRC Handbook of Chemistry and Physics, 92nd ed., CRC Press, Boca Raton, FL, 2011.

[49] E.I. Popov, L.Y. Kashporov, V.M. Mal'tsev, A.L. Breiter, Combust. Explos. Shock Waves 9 (1973) 204-8.

[50] B. Müller, U. Renz, Rev. Sci. Instrum. 72 (2001) 3366-74.

[51] K.R. Overdeep, T.P. Weihs, J. Therm. Anal. Calorimetry- To Be Submitt. 2015 (n.d.).

[52] Y. Zhong, M. Yang, Z.-K. Liu, Calphad Comput. Coupling Phase Diagrams Thermochem. 29 (2005) 303-11.

[53] H. Okamoto, J. Phase Equilibria 23 (2002) 455-56.

[54] H. Okamoto, J. Phase Equilibria Diffus. 28 (2007) 305-6.

[55] P.J. Linstrom, W.G. Mallard, NIST Stand. Ref. Database 69 (2011).

[56] F.R. de Boer, R. Boom, W.C.M. Mattens, A.R. Miedema, A.K. Niessen, Cohesion in Metals: Transition Metal Alloys, Elsevier Science Publishers B.V., Amsterdam, 1989.

[57] J.C. Pickering, A.P. Thorne, J.K. Webb, Mon. Not. R. Astron. Soc. 300 (1998) 131-34.

[58] P.C. Mahanti, Phys. Rev. 42 (1932) 609-24.

[59] L. Brewer, S. Trajmar, J. Chem. Phys. 36 (1962) 1585-87.

[60] W.C. Pomeroy, Phys. Rev. 29 (1927) 59-79.

[61] M. Kunz, C. Klingshirn, H. Kretschmann, W. Assmus, Mater. Chem. Phys. 25 (1990) $27-41$.

[62] F. Lowater, Proc. Phys. Soc. 44 (1932) 51-66.

[63] R.E. Honig, RCA Rev. 18 (1957) 195.

[64] L.S. Nelson, Nature 207 (1965) 741.

[65] R.T. Meyer, L.S. Nelson, High Temp. Sci. 2 (1970) 35-57.

[66] I.E. Molodetsky, E.L. Dreizin, C.K. Law, Symp. Combust. 26 (1996) 1919-27. 
[67] E.L. Dreizin, Prog. Energy Combust. Sci. 26 (2000) 57-78.

[68] G.R. Fischer, L.J. Manfredo, R.N. McNally, R.C. Doman, J. Mater. Sci. 16 (1981) 3447-51.

[69] V.G. Zavodinsky, Phys. Solid State 46 (2004) 453-57.

[70] H. Kwak, S. Chaudhuri, Surf. Sci. 604 (2010) 2116-28.

[71] F. Czerwinski, Acta Mater. 50 (2002) 2639-54.

[72] M. Paljevid, 204 (1994) 119-26.

[73] F.T. Mackenzie, Our Changing Planet, Prentice-Hall, Upper Saddle River, NJ, 1995. 
Captions for Figures in the manuscript body:

Figure 1: Nanolaminate Reaction Schematic. Rapid self-propagating formation reactions occur in metallic multilayer foils after a small energy input, and can be followed by slower oxidation and/or nitridation in air. Only a small number of layers are shown; in reality, foils contain hundreds of layers.

Table 1: Compositions of each foil in at.\% based on elemental analysis by ICP-OES

Figure 2: Still Frames from High Speed Videos. These still frames show a. Al:Zr, b. Al$8 \mathrm{Mg}: \mathrm{Zr}$, and c. Al-38Mg:Zr foils reacting. Each foil is reacted suspended horizontally in air, and ignited using a spark on the edge towards the left side of frame. The full lengths of all three foil types burn brightly, but the Mg-containing foils appear dark in the images because the camera aperture was closed more to prevent the much brighter Mg clouds from oversaturating the detector. The green coloration in the video of an $\mathrm{Al}-8 \mathrm{Mg}: \mathrm{Zr}$ foil reacting is also the result of the camera settings and is not scientifically relevant. I would like each still frame to link to the corresponding videos when viewing online.

Figure 3: Pyrometry Results. a. Temperature profiles of the three compositions reacting in air. Each sample is approximately $40 \mu \mathrm{m}$ thick. Temperatures are given as $\mathrm{T}$ as well as $\mathrm{T}^{4}$, because area under $\mathrm{T}^{4}$ curves is thought to scale with radiative heat loss [31]. $\mathrm{b}$. The repeatability of the measurements is demonstrated with similar samples of $\mathrm{Al}-8 \mathrm{Mg}: \mathrm{Zr}$ ( $\approx 40 \mu \mathrm{m}$ thick, with $\mathrm{a} \approx 56 \mathrm{~nm}$ bilayer spacing) reacted in air. The pyrometer is only sensitive to temperatures above $1000 \mathrm{~K}$ and hence the apparent baseline is misleading as it represents all temperatures below $1000 \mathrm{~K}$.

Figure 4: Bomb Calorimetry Results. Data is reported in $\mathrm{kJ} \mathrm{g}^{-1}$ for each composition and environment, showing experimental values (dark segments) as well as the theoretical maximum values calculated for $100 \%$ combustion efficiency (faded segments).

Figure 5: Reacted Foil Morphologies. Microprobe (a,b,d,f) and SEM (c,e) cross sections of each foil after reacting in air, with mosaics providing morphological comparisons for entire foil widths on the left, and detailed high magnification images on the right. The schematic in the top-left corner shows a foil mounted on the ignition frame, highlighting the plane at which the foils were fractured to obtain these cross sections.

Table 2: Comparison of post-reaction nitrogen and oxygen levels (in at.\%) at the interior of each foil after reacting in air.

Figure 6: Vapor Characterization. Spectroscopic characterization of the vapor released from an $\mathrm{Al}-8 \mathrm{Mg}: \mathrm{Zr}$ foil, with an $\mathrm{Al}: \mathrm{Zr}$ foil shown for comparison. The reaction starts at $\mathrm{t}=0$. The peaks persist for varying durations, and the particular spectra shown were selected for optimal signal to noise ratio. (a) Absorption at lower wavelengths from foils reacted in air, measured at $\mathrm{t}=0.15 \pm .01 \mathrm{~s}$. (b) Absorption at lower wavelengths from foils reacted in argon, measured at $\mathrm{t}=0.11 \pm .01 \mathrm{~s}$. (c) Emission at higher wavelengths from foils reacted in air, measured at $\mathrm{t}=0.03 \pm .01 \mathrm{~s}$.

Figure 7: Particle Characterization. TEM images of particles ejected in air that were analyzed for chemical composition. The particles of interest appear as dark shapes adhered to 
the grey, web-like structure, which is the holey-carbon support film. Lighter areas are open spaces. (a) Single metal-oxide particles with a wide range of sizes and shapes. Representative particles are labeled, though size and shape of each metal oxide varies widely. (b) A cubic $\mathrm{MgO}$ single crystal at higher magnification.

Figure 8: Mass of Each Metal Ejected. Results from ICP-OES tests detail the fate of each metal after reacting foils in air, presented in atomic percent of the initial foil content. The main area of each chart corresponds to the atomic percent of each metal remaining in the foil. The expanded segments show the atomic percent of each metal ejected. The initial concentration of each metal in the foil before reacting is the sum of the ejected and remaining mass for that metal. 

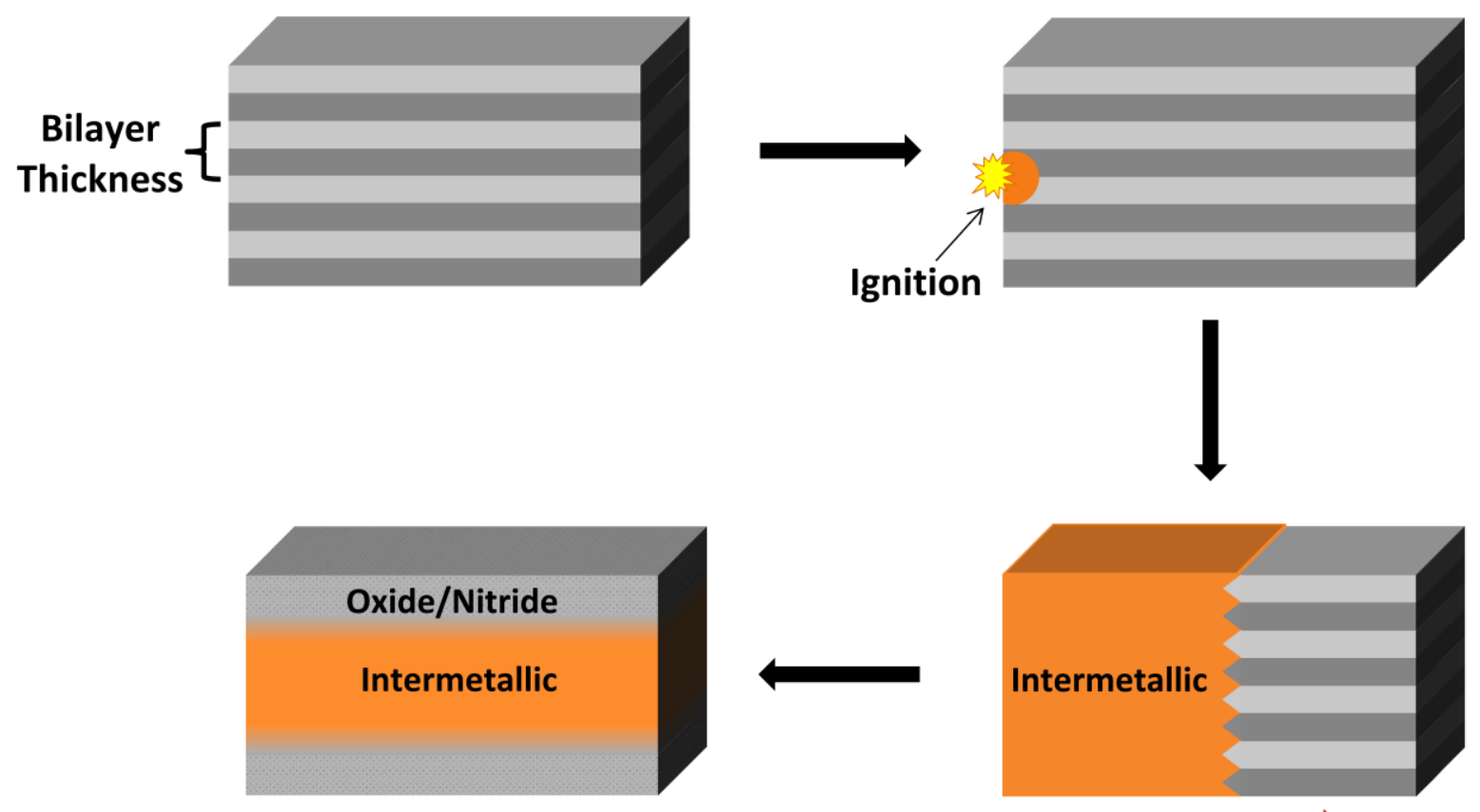

Reaction Propagation

Fig. 1 


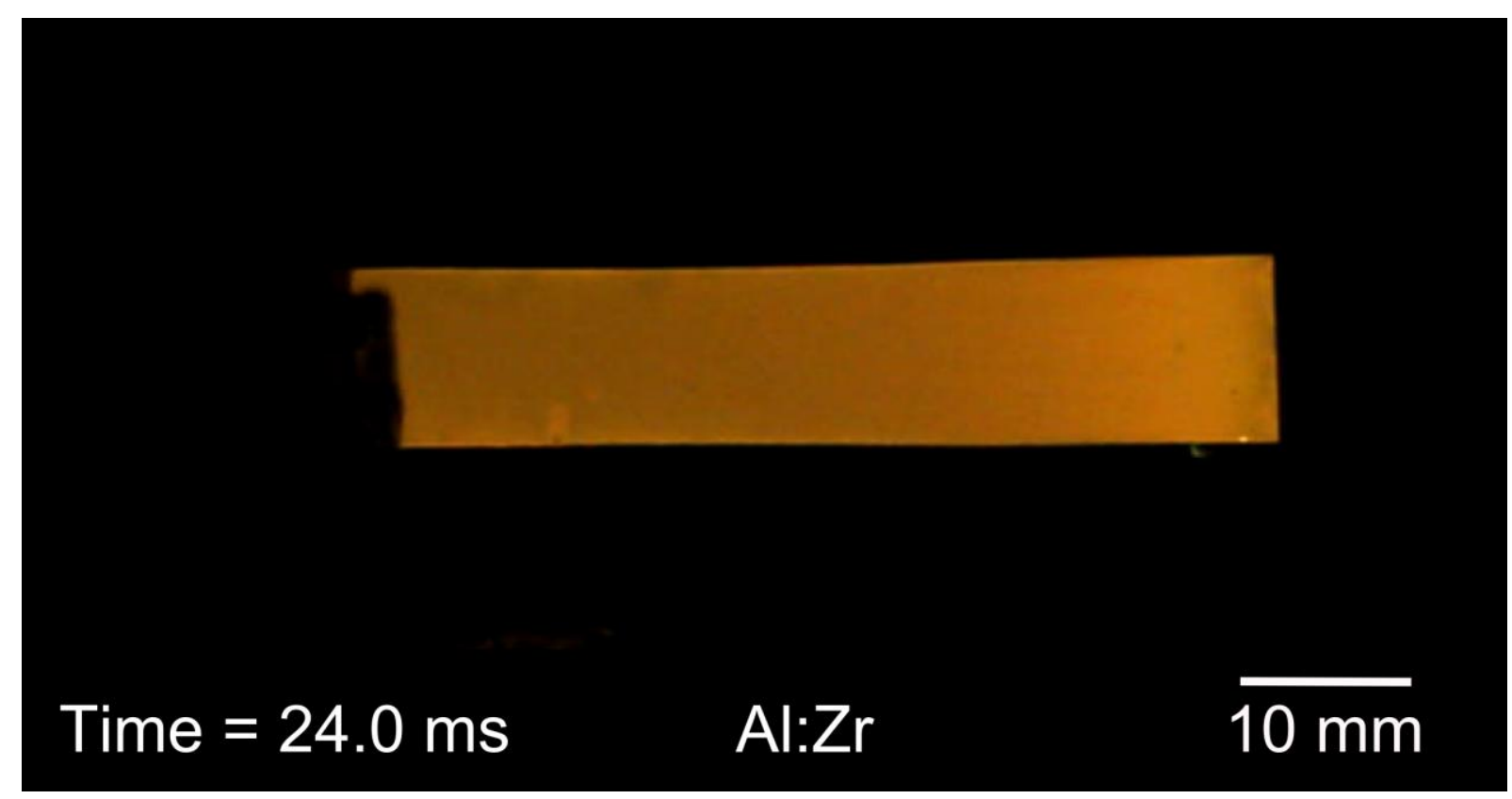

Fig. 2a

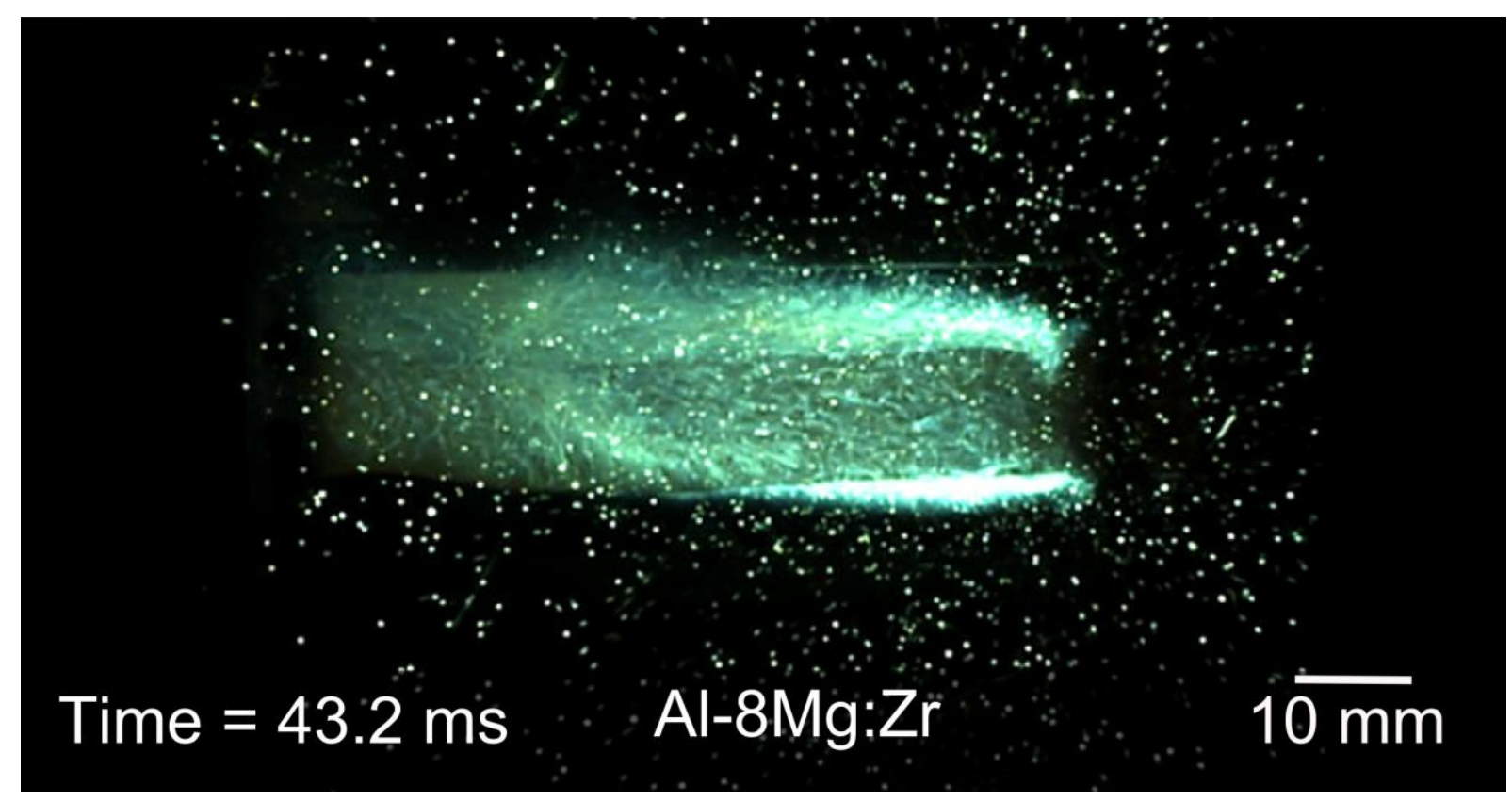

Fig. 2b 


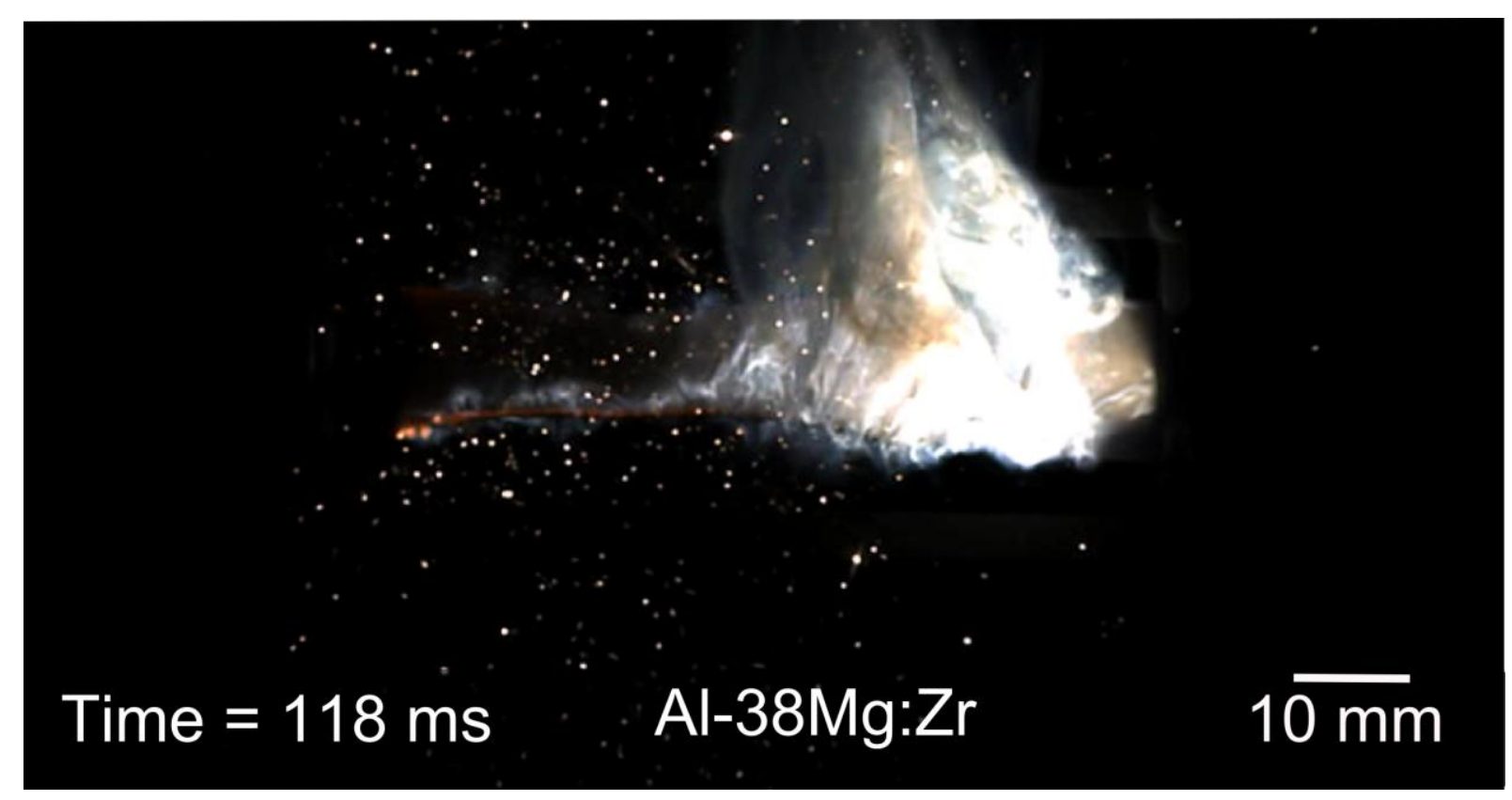

Fig. 2c 

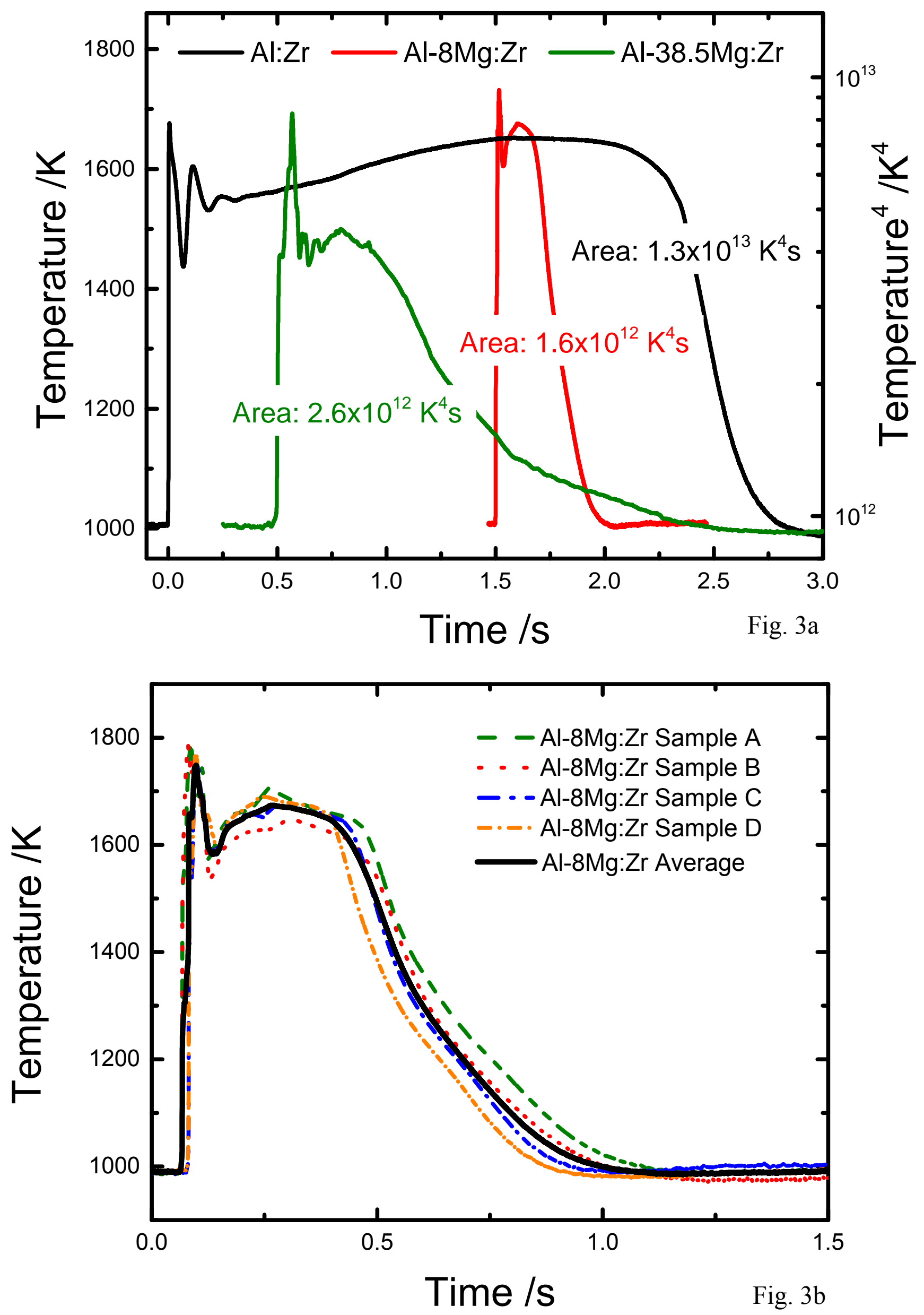


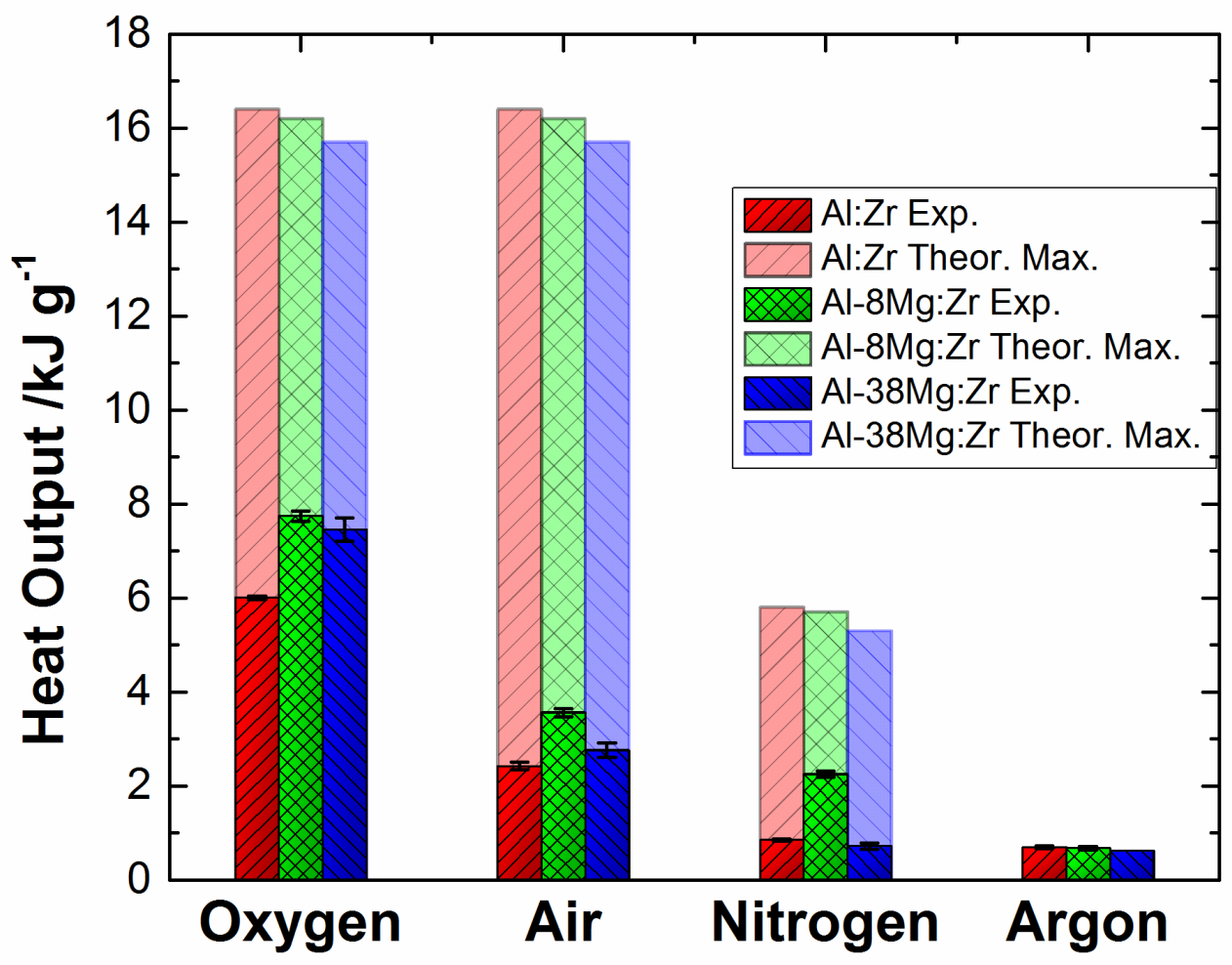

Fig. 4 


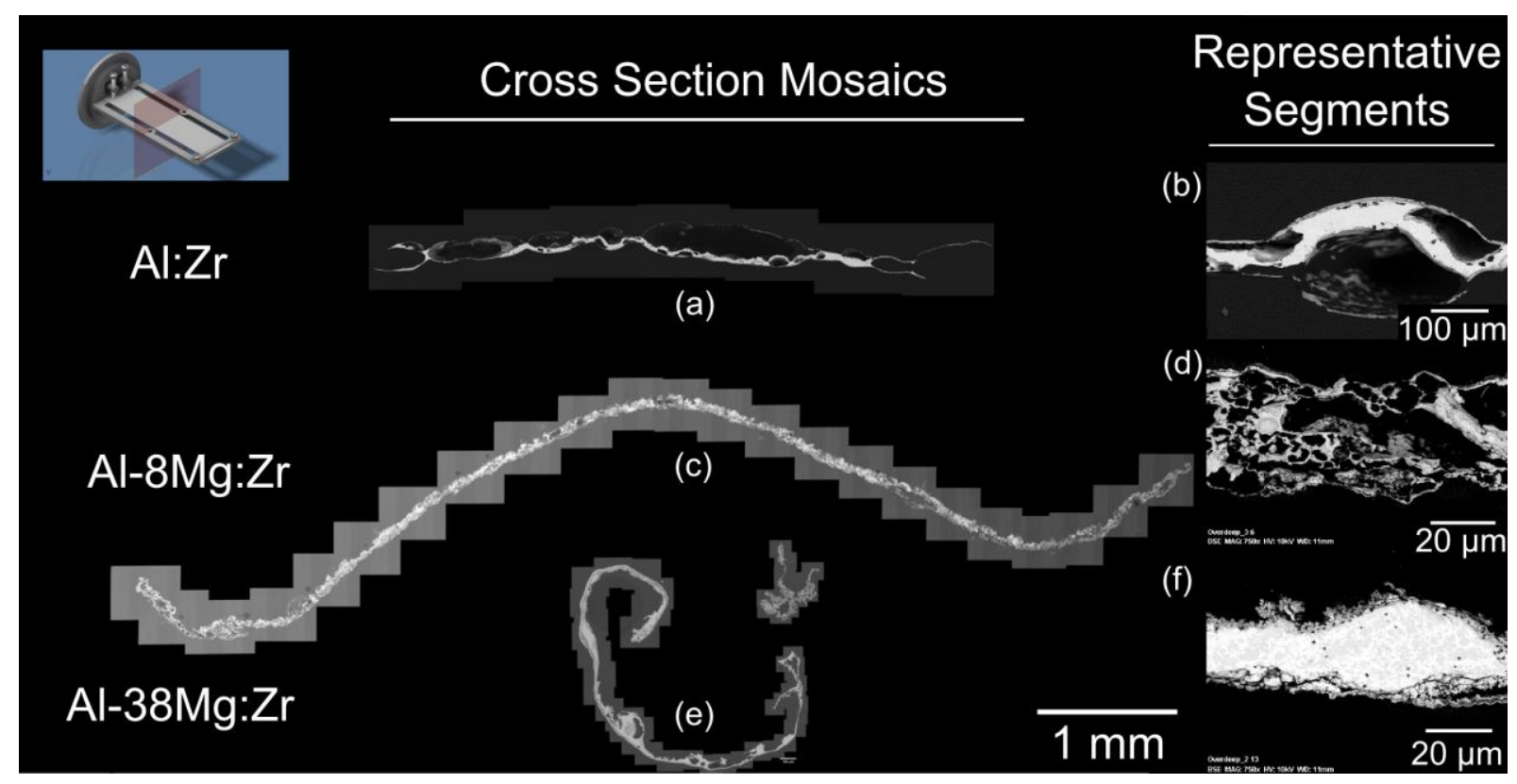

Fig. 5 


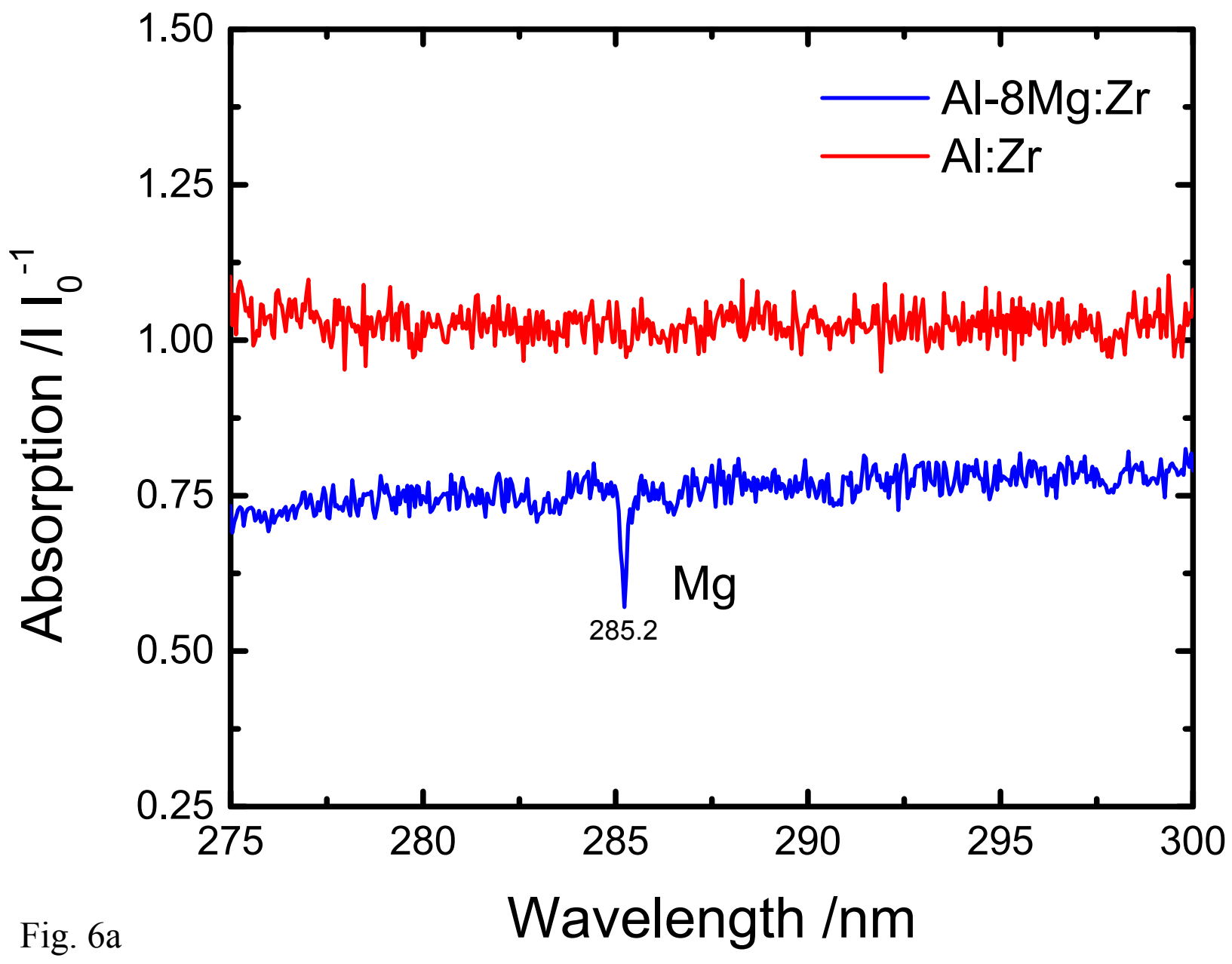




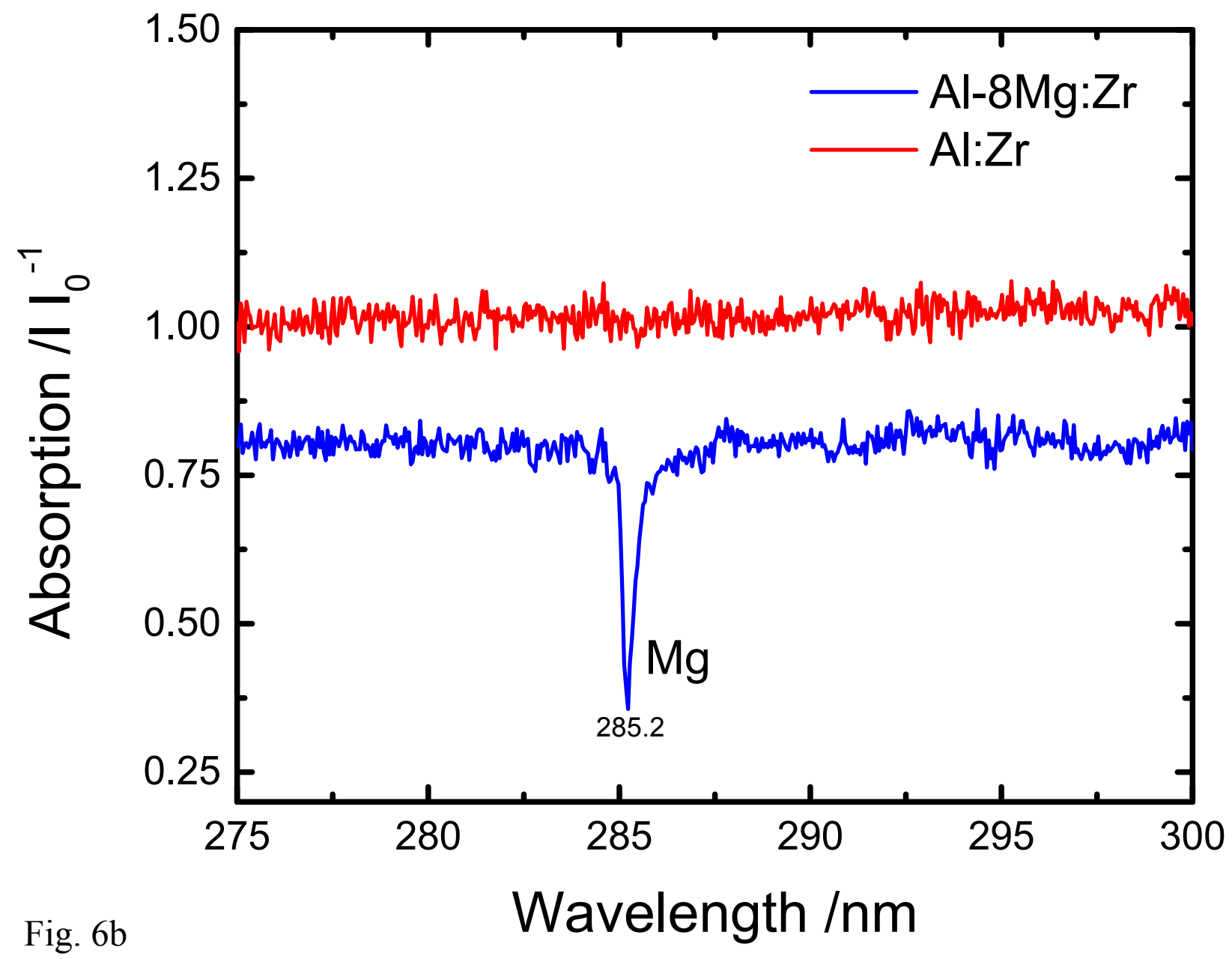




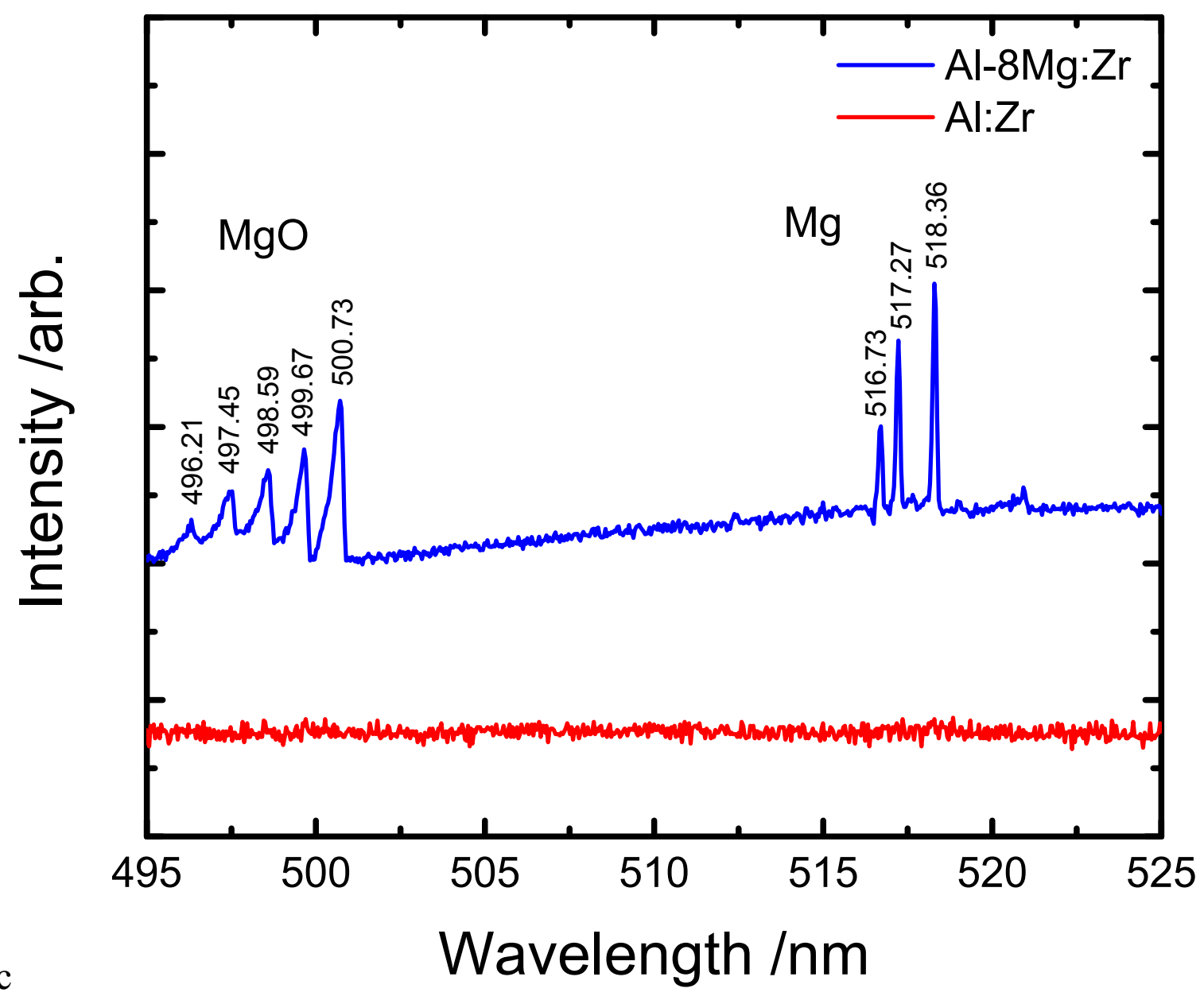

Fig. 6c 


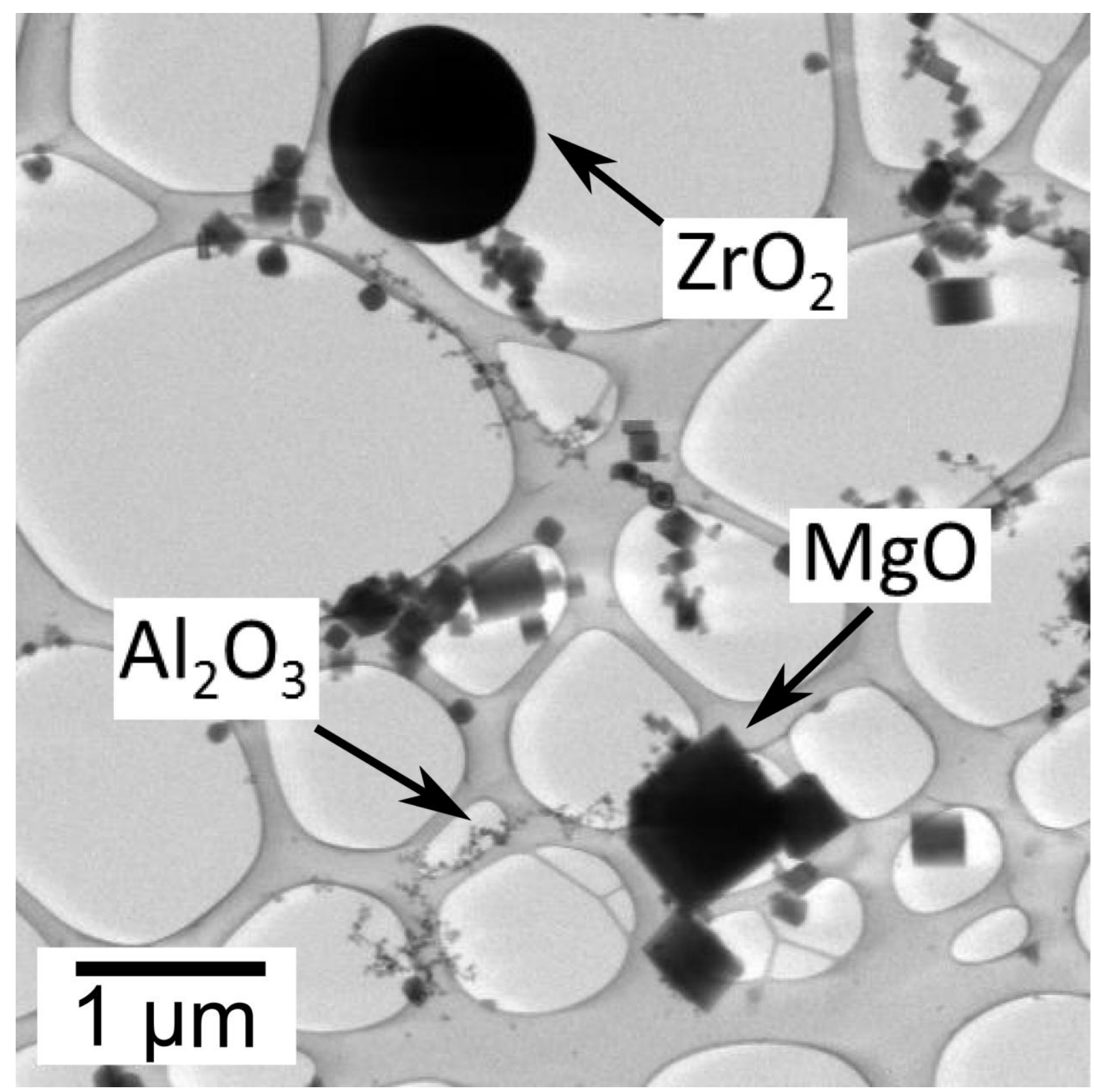

Fig. 7b 


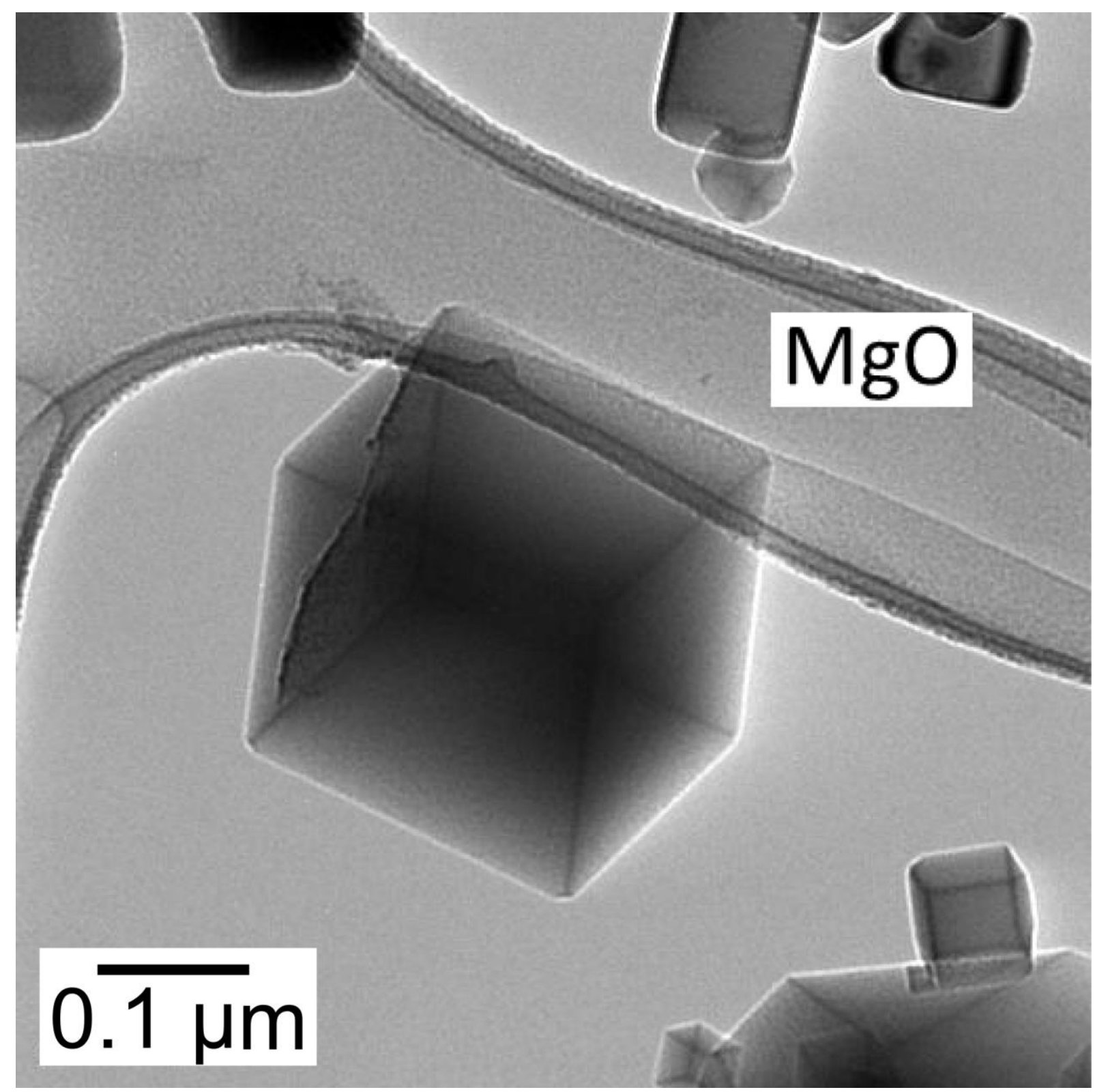

Fig. 7a 

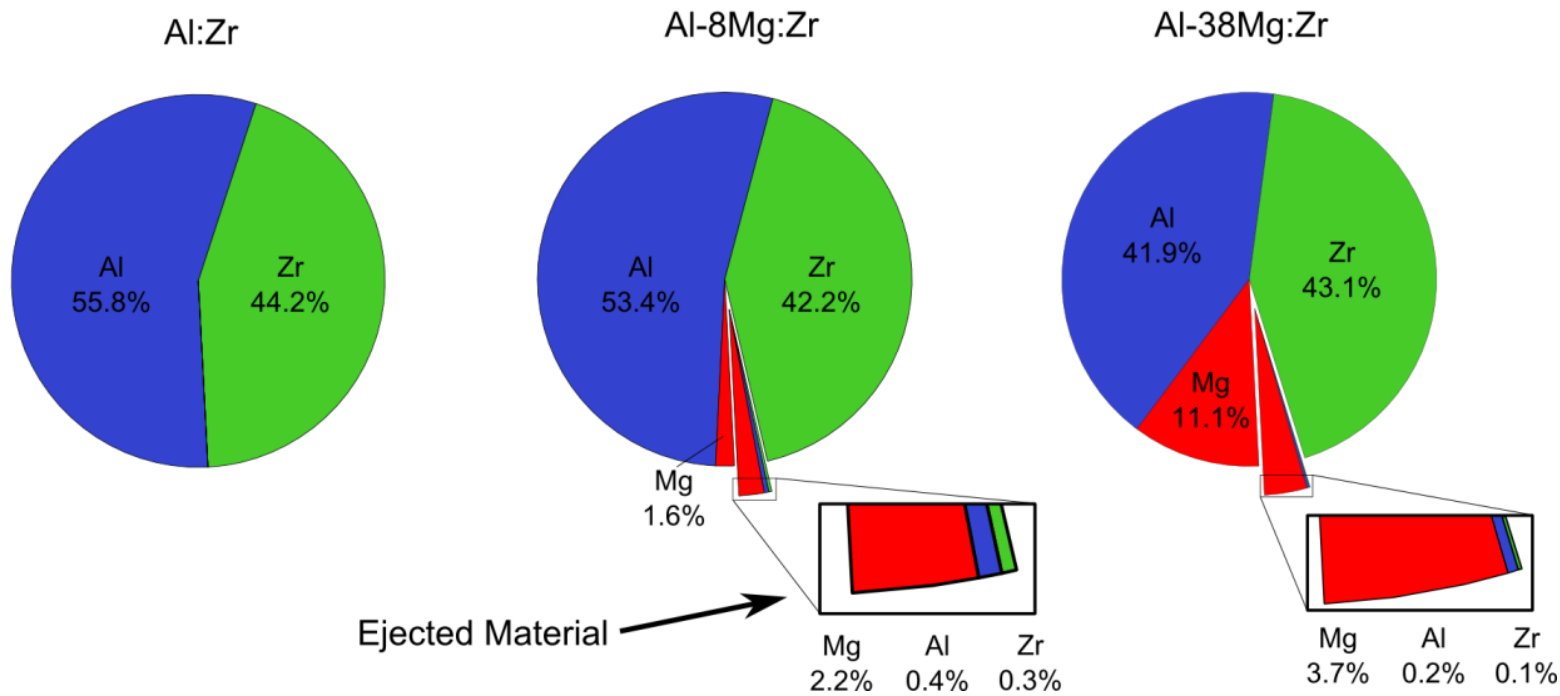

Fig. 8 
Table $1 \quad$ Measured Foil Compositions [at.\%]
Al:Zr
Al-8Mg:Zr
Al-38.5Mg:Zr
0.0
3.8
14.7
53.8
42.1
44.2
42.5
43.2

Mg

Al $\quad 55.8$

$\mathbf{Z r}$ 
Table 2

Oxygen

Nitrogen

Average concentration at the foil center [at.\%]

Al:Zr Al-8Mg:Zr

4.16

6.25
14.37

28.15
Al-38.5Mg:Zr

5.75

7.37 